\title{
BIOACTIVE GLASS INDUCED OSTEOGENIC DIFFERENTIATION OF HUMAN ADIPOSE STEM CELLS IS DEPENDENT ON CELL ATTACHMENT MECHANISM AND MITOGEN-ACTIVATED PROTEIN KINASES
}

\author{
M. Ojansivu ${ }^{1,2 *}$, X. Wang ${ }^{3}$, L. Hyväri ${ }^{1,2}$, M. Kellomäki ${ }^{1,4}$, L. Hupa ${ }^{3}$, S. Vanhatupa ${ }^{1,2 \S}$ and S. Miettinen ${ }^{1,2 \S}$ \\ ${ }^{1}$ Faculty of Medicine and Life Sciences and BioMediTech Institute, University of Tampere, Tampere, \\ Finland \\ 2 Science Centre, Tampere University Hospital, Tampere, Finland \\ ${ }^{3}$ Johan Gadolin Process Chemistry Centre, Åbo Akademi University, Turku, Finland \\ ${ }^{4}$ Faculty of Biomedical Science and Engineering and BioMediTech Institute, \\ Tampere University of Technology, Tampere, Finland \\ $\S$ These authors contributed equally to the work.
}

\begin{abstract}
Bioactive glasses (BaGs) are widely utilised in bone tissue engineering (TE) but the molecular response of cells to BaGs is poorly understood. To elucidate the mechanisms of cell attachment to BaGs and BaG-induced early osteogenic differentiation, we cultured human adipose stem cells (hASCs) on discs of two silica-based $\mathrm{BaGs}$ S53P4 (23.0 Na $\mathrm{O}_{2}-20.0 \mathrm{CaO}-4.0 \mathrm{P}_{2} \mathrm{O}_{5}-53.0 \mathrm{SiO}_{2}($ wt- $\%)$ ) and 1-06 $\left(5.9 \mathrm{Na}_{2} \mathrm{O}-12.0 \mathrm{~K}_{2} \mathrm{O}-5.3 \mathrm{MgO}-22.6 \mathrm{CaO}-4.0 \mathrm{P}_{2} \mathrm{O}_{5}-0.2 \mathrm{~B}_{2} \mathrm{O}_{3}-50.0 \mathrm{SiO}_{2}\right.$ ) in the absence of osteogenic supplements. Both $\mathrm{BaGs}$ induced early osteogenic differentiation by increasing alkaline phosphatase activity (ALP) and the expression of osteogenic marker genes RUNX2a and OSTERIX. Based on ALP activity, the slower reacting 1-06 glass was a stronger osteoinducer. Regarding the cell attachment, cells cultured on $\mathrm{BaGs}$ had enhanced integrin $\beta 1$ and vinculin production, and mature focal adhesions were smaller but more dispersed than on cell culture plastic (polystyrene). Focal adhesion kinase (FAK), extracellular signal-regulated kinase (ERK1/2) and c-Jun N-terminal kinase (JNK)-induced c-Jun phosphorylations were upregulated by glass contact. Moreover, the BaG-stimulated osteoinduction was significantly reduced by FAK and mitogenactivated protein kinase (MAPK) inhibitors, indicating an important role for FAK and MAPKs in the BaGinduced early osteogenic commitment of hASCs. Upon indirect insert culture, the ions released from the $\mathrm{BaG}$ discs could not reproduce the observed cellular changes, which highlighted the role of direct cell-BaG interactions in the osteopotential of BaGs. These findings gave valuable insight into the mechanism of BaG-induced osteogenic differentiation and therefore provided knowledge to aid the future design of new functional biomaterials to meet the increasing demand for clinical bone TE treatments.
\end{abstract}

Keywords: Mesenchymal stem cell, bioactive glass, osteogenic differentiation, cell attachment, focal adhesion, mitogen-activated protein kinase, cell signalling.

* Address for correspondence: Miina Ojansivu, University of Tampere, ARVO / BMT / Regenerative Medicine / Adult Stem Cell Group, 33014 University of Tampere, FINLAND

Telephone: +358504947925

Email: miinaojansivu@hotmail.com

\section{Introduction}

Of the various biomaterials tested for bone tissue engineering (TE) applications, bioactive glasses (BaGs) are proven to be especially advantageous due to their strong bonding to bone, biocompatibility and biodegradation, but most importantly due to their inherent ability to stimulate the osteogenic differentiation of stem and progenitor cells (Jones, 2013; Rahaman et al., 2011). Of the different BaG compositions S53P4 (23.0 $\mathrm{Na}_{2} \mathrm{O}-20.0 \mathrm{CaO}-4.0$ $\mathrm{P}_{2} \mathrm{O}_{5}-53.0 \mathrm{SiO}_{2}(\mathrm{wt}-\%)$ ), commercially available as BonAlive ${ }^{\circledR}$, is known to induce osteogenic differentiation in vitro (Waselau et al., 2012), and to support bone formation in in vivo models (Peltola et al., 2001; Virolainen et al., 1997) as well as in clinical settings (Lindfors et al., 2010; Sandor et al., 2014; Turunen et al., 2004). In addition to the well-known glass formulations, novel glass compositions are being constantly developed to further improve the glass properties. One interesting experimental silicabased glass type is $1-06\left(5.9 \mathrm{Na}_{2} \mathrm{O}-12.0 \mathrm{~K}_{2} \mathrm{O}-5.3 \mathrm{MgO}\right.$ - 22.6 $\mathrm{CaO}$ - 4.0 $\mathrm{P}_{2} \mathrm{O}_{5}-0.2 \mathrm{~B}_{2} \mathrm{O}_{3}-50.0 \mathrm{SiO}_{2}$ (wt-\%)), which contains oxides of potassium, magnesium and 
boron. 1-06 shows good bone tissue bonding in vivo (Madanat et al., 2009) but otherwise the behaviour of this experimental glass in biological settings remains largely unknown.

When considering bone TE, it is important to understand how different signalling pathways guide the cell functions in response to biomaterial contacts. Despite the vast number of studies conducted with BaGs, very little is currently known about the cell signalling events related to the BaG-induced cellular responses. Au and co-workers (Au et al., 2010) show fluctuation in the gene expression levels of mitogenactivated protein kinases (MAPKs) in MG-63 cell line cultured on Consil ${ }^{\circledR}$ Bioglass ${ }^{\circledR}$ particles, and two other studies report activation of focal adhesion kinase (FAK) and MAPKs in human dental pulp cells in contact with BaG containing composites (Kim et al., 2015; Zhang et al., 2015). However, in these studies, the signalling protein activation is not linked to the osteogenic response and, since the BaGs are part of composites, the effect induced solely by BaGs cannot be distinguished.

Anchorage-dependent cells attach to the growth surface by means of transmembrane integrins, which are composed of two subunits, the $\alpha$ chain and the $\beta$ chain (Hynes, 2002). Integrins form the core of the cell adhesion sites called focal adhesions (FAs), which connect the extracellular matrix (ECM) to the cytoskeleton and initiate several intracellular signalling cascades (Burridge and ChrzanowskaWodnicka, 1996). Since the integrins lack enzymatic activity, the cell attachment initiated integrinmediated signal transmission relies primarily on non-receptor protein tyrosine kinases, which associate with the cytoplasmic tails of the integrins. The most notable of these protein kinases is FAK, which regulates various cellular processes ranging from migration, survival and cell cycle control to differentiation (Schaller, 2001). With respect to the osteogenic differentiation it is reported that natural ECM simulating collagen-I and laminin surfaces support osteogenic differentiation of mesenchymal stem cells and osteoblastic cells via the FAK-extracellular signal-regulated kinase (ERK1/2) signalling route (Salasznyk et al., 2007a; Salasznyk et al., 2007b; Shih et al., 2011; Takeuchi et al., 1997; VialeBouroncle et al., 2014a; Viale-Bouroncle et al., 2014b). Furthermore, elevated FAK activation is observed in cells cultured on bioceramic materials (Kim et al., 2015; Marino et al., 2010; Shie and Ding, 2013).

Apart from being an important player in the cell attachment-induced signalling cascades downstream of FAK, MAPK ERK1/2 is regulated by a variety of other stimuli including growth factors and cytokines (Rubinfeld and Seger, 2005). Several studies indicate the important role of ERK1/2 in the osteogenic differentiation induced solely by chemical supplements (Jaiswal et al., 2000; Lai et al., 2001; Liu et al., 2009). In addition to ERK1/2, MAPKs p38 and c-Jun $\mathrm{N}$-terminal kinases (JNKs) are also tightly connected to the regulation of osteogenic differentiation. Both of them are known to be involved in both the cell attachment-related signalling cascades (Chiu et al., 2014; Ivaska et al., 1999) as well as in chemical stimuli induced osteogenesis (Gu et al., 2015; Suzuki et al., 2002; Tominaga et al., 2005).

In the present study, it was hypothesised that cell attachment on the BaG surface plays a role in the BaG-induced early osteogenic differentiation of human adipose stem cells (hASCs), and both FAK and MAPKs have a distinct function in the glass-induced bone formation. There was also an interest in comparing the effect of two different glass compositions, S53P4 and 1-06, on the cellular responses. To examine the validity of the hypothesis, the attachment and ECM formation of hASCs on S53P4 and 1-06 glasses were analysed and the roles of FAK and MAPKs in the glass-induced early osteogenic differentiation were determined. In order to observe the osteogenic differentiation induced solely by the BaGs, no osteogenic supplements were used. Human ASCs were chosen due to their wellknown ability to differentiate towards osteoblastic phenotype in vitro and their successful utilisation in clinical bone TE-based treatments (Detsch et al., 2015; Haimi et al., 2009a; Haimi et al., 2009b; Larranaga et al., 2015; Marino et al., 2010; Ojansivu et al., 2015; Sandor et al., 2014; Waselau et al., 2012). To characterise the material properties possibly affecting cell behaviour, the roughness of the glasses as well as the dissolution and surface structures of the BaGs were studied. The cellular effect of ions released from the BaG discs in the absence of direct cell-biomaterial contact were also evaluated. As far as is known, this is the first study evaluating the cell attachment and osteogenic differentiation related cell signalling mechanisms on BaGs.

\section{Materials and Methods}

\section{Ethics statement}

This study was conducted in accordance with the Ethics Committee of the Pirkanmaa Hospital District, Tampere, Finland (R15161). The hASCs were isolated from adipose tissue samples obtained from surgical procedures conducted in the Department of Plastic Surgery, Tampere University Hospital. There were five female donors of age $56 \pm 8$ years. All the donors gave a written informed consent for the utilisation of the adipose tissue samples in the research settings.

\section{Manufacturing of the BaG discs and their pre- treatment}

Bioactive glasses S53P4 and 1-06 were prepared as described previously (Ojansivu et al., 2015) (for the oxide compositions, see Table 1). The melt was cast to give rods, which after annealing were cut into circular discs, the thickness of which was $1.5 \mathrm{~mm}$ and the diameter either $7 \mathrm{~mm}$ (ionic release analyses; this was the maximum size to fit to the 24-well inserts), $10 \mathrm{~mm}$ (immunocytochemical stainings (ICCs)) or 
Table 1. The nominal compositions of S53P4 and 1-06 BaGs.

\begin{tabular}{|l|l|l|l|l|l|l|l|}
\hline & \multicolumn{7}{|c|}{ wt-\% } \\
\cline { 2 - 8 } & $\mathrm{Na}_{2} \mathrm{O}$ & $\mathrm{K}_{2} \mathrm{O}$ & $\mathbf{M g O}$ & $\mathrm{CaO}$ & $\mathbf{P}_{2} \mathrm{O}_{5}$ & $\mathbf{B}_{2} \mathrm{O}_{3}$ & $\mathrm{SiO}_{2}$ \\
\hline S53P4 & 23.0 & 0.0 & 0.0 & 20.0 & 4.0 & 0.0 & 53.0 \\
\hline $\mathbf{1 - 0 6}$ & 5.9 & 12.0 & 5.3 & 22.6 & 4.0 & 0.2 & 50.0 \\
\hline
\end{tabular}

$14 \mathrm{~mm}$ (other analyses). Both sides of the discs were polished with wet polishing paper, of which the finest was 2,500 grit. Prior to the cell culture, the discs were disinfected with $70 \%$ ethanol as described by Ojansivu et al. (2015). The discs were pre-incubated in cell culture medium overnight before plating the cells.

\section{Adipose stem cell isolation and culture}

The isolation of hASCs was conducted using a published mechanical and enzymatic procedure (Tirkkonen et al., 2013; Zuk et al., 2001). The isolated hASCs were maintained in T-75 polystyrene flasks (Nunc, Thermo Fisher Scientific, Waltham, MA, USA) in DMEM/F-12 (Life Technologies, Thermo Fisher Scientific) supplemented with $5 \%$ human serum (HS; PAA Laboratories, GE Healthcare, Little Chalfont, Buckinghamshire, United Kingdom), $1 \%$ L-glutamine (GlutaMAX I, Life Technologies, Thermo Fisher Scientific) and $1 \%$ antibiotics (100 U/mL penicillin and $0.1 \mathrm{mg} / \mathrm{mL}$ streptomycin; BioWittaker, Lonza, Basel, Switzerland). To verify the mesenchymal origin of the hASCs, the surface marker expression was determined at passage 1 using flow cytometric analysis (FACSAria, Becton, Dickinson and Company, Erembodegem, Belgium) (Lindroos et al., 2009). The hASCs used in the experiments had strong expression for surface markers CD73, CD90 and CD105, whereas the expression of CD3, CD11a, CD14, CD19, CD45, CD80, CD86, HLA-DR, CD34 and CD54 was very low or moderate, thus confirming the mesenchymal origin of the hASCs. Cells used in the experiments were in passages $2-5$. All the experiments were conducted with non-pooled hASCs from 2-4 donors.

The plating density was 1,100 cells $/ \mathrm{cm}^{2}$ except in Western blot studies it was 11,100 cells $/ \mathrm{cm}^{2}$. Control cells were grown in cell culture plastic (polystyrene). The medium composition in the experiments was otherwise the same as the maintenance medium described above except that the HS was treated with dextran coated charcoal (DCC; Sigma-Aldrich, St. Louis, MO, USA; according to the manufacturer's protocol) to strip hormones from the serum, to observe the BaG-induced signalling events better. No osteogenic medium supplements were used in order to detect the differentiation caused solely by the BaGs. FAK and MAPKs were inhibited during the culture using the following inhibitors: FAK $2 \mu \mathrm{M}$ PF562271 (Selleckchem, Munich, Germany), MEK-ERK $60 \mu \mathrm{M}$ PD98059 (Calbiochem, Merck Millipore, Billerica, MA, USA), p38 $2 \mu$ M SB202190 (Calbiochem, Merck Millipore) and JNK $10 \mu \mathrm{M}$ SP600125 (Selleckchem). The media were changed twice a week.
To distinguish the effects of $\mathrm{BaG}$ ions released from the discs on early osteogenic differentiation and signalling mechanisms, the discs were placed in cell culture inserts (ThinCert ${ }^{\mathrm{TM}}$ Cell Culture Inserts 24 well, Greiner Bio-One, Kremsmünster, Austria). This enabled the evaluation of ionic exposure on cells cultured on the bottom of the wells without a direct glass contact. The culture was conducted in maintenance medium supplemented with $5 \%$ DCC-treated HS (Biowest, Nuaillé, France) and all the direct culture groups (S53P4, 1-06 and control polystyrene) were also included in the experiment as controls.

\section{Cell Viability and proliferation}

Cell viability on the different materials and in the presence of the inhibitors was analysed after $21 \mathrm{~d}$ of culture, by Live/Dead staining (Invitrogen, Thermo Fisher Scientific). In short, cells were treated with a working solution containing $0.25 \mu \mathrm{M}$ EthD-1 (stains dead cells red) and $0.5 \mu \mathrm{M}$ Calcein-AM (stains living cells green) for $20 \mathrm{~min}$ at room temperature. After the incubation, samples were imaged immediately using fluorescence microscopy (IX51, Olympus, Tokyo, Japan).

Cell proliferation was studied at the $21 \mathrm{~d}$ time point by determining the relative DNA amounts using CyQUANT Cell Proliferation Assay kit (Invitrogen, Thermo Fisher Scientific), according to the manufacturer's protocol. Cells were lysed with $0.1 \%$ Triton-X 100 lysis buffer (Sigma-Aldrich), and after one freeze-thaw-cycle $\left(-70^{\circ} \mathrm{C}\right)$, three parallel $20 \mu \mathrm{L}$ samples of each lysate were pipetted into a 96well plate (Nunc) and mixed with $180 \mu \mathrm{L}$ working solution containing CyQUANT GR dye and cell lysis buffer. The fluorescence at $480 / 520 \mathrm{~nm}$ was measured using a Victor 1420 Multilabel counter (Wallac, Turku, Finland).

\section{Alkaline phosphatase activity}

To analyse the early osteogenic differentiation, alkaline phosphatase (ALP) activity was determined quantitatively at $21 \mathrm{~d}$, as previously described (Ojansivu et al., 2015; Tirkkonen et al., 2013), using an ALP kit from Sigma. The ALP activities were analysed from the same cell lysates as the proliferation, and the results were normalised by dividing by the cell proliferation values. A relatively late time point for ALP activity was chosen, based on preliminary optimisations. It was important to study the osteogenic differentiation induced solely by the glasses. In the absence of any other osteogenic supplements, the differentiation requires a longer time.

\section{Quantitative real-time PCR}

The relative expression of osteogenic marker genes RUNX $2 a$ and OSTERIX was measured at $14 \mathrm{~d}$ and $21 \mathrm{~d}$ using the quantitative real-time reverse transcription polymerase chain reaction (qRT-PCR) (Kyllönen et al., 2013; Ojansivu et al., 2015). The data 
Table 2. The Sequences of the primers used in qRT-PCR.

\begin{tabular}{|c|c|c|c|}
\hline Name & $5^{\prime}$-Sequence-3' & Product size $(\mathrm{bp})$ & Accession Number \\
\hline \multirow{2}{*}{ OSTERIX } & forward TGAGCTGGAGCGTCATGTG & \multirow{2}{*}{79} & \multirow{2}{*}{ AF477981 } \\
\hline & reverse TCGGGTAAAGCGCTTGGA & & \\
\hline \multirow{2}{*}{ RPLP0 } & forward AATCTCCAGGGGCACCATT & \multirow{2}{*}{70} & \multirow{2}{*}{ NM_001002 } \\
\hline & reverse CGCTGGCTCCCACTTTGT & & \\
\hline \multirow{2}{*}{ RUNX2a } & forward CTTCATTCGCCTCACAAACAAC & \multirow{2}{*}{62} & \multirow{2}{*}{ NM_001024630.3 } \\
\hline & reverse TCCTCCTGGAGAAAGTTTGCA & & \\
\hline
\end{tabular}

were normalised to the expression of housekeeping gene human acidic ribosomal phosphoprotein PO (RPLPO). In the calculation of relative expressions, a published mathematical model was used (Pfaffl, 2001). The sequences of the primers (Oligomer Oy, Helsinki, Finland) and the accession numbers of the genes are depicted in Table 2.

\section{Immunocytochemical staining}

The amount and localisation of cell-attachmentrelated vinculin at $24 \mathrm{~h}$ and $7 \mathrm{~d}$, as well as ECM proteins collagen-I and fibronectin at $21 \mathrm{~d}$, were studied using published ICCs methods (Ojansivu et al., 2015). The following primary antibodies were used: vinculin ABfinity ${ }^{\mathrm{TM}}$ recombinant rabbit antibody (Life Technologies, Thermo Fisher Scientific; dilution 1:100), mouse monoclonal anti-collagen-I (Abcam, Cambridge, United Kingdom; dilution 1:2000) and mouse anti-human fibronectin (Merck Millipore; dilution 1:200). The secondary antibodies (donkey anti-rabbit Alexa fluor 488 IgG for vinculin and donkey anti-mouse Alexa fluor 488 IgG for collagen-I and fibronectin; both from Invitrogen, Thermo Fisher Scientific; dilution 1:800) were applied together with actin-staining phalloidin-TRITC (Sigma-Aldrich, dilution 1:500). The nuclei were stained with 4',6-diamidino-2-phenylindole (DAPI) (Molecular Probes, Thermo Fisher Scientific; dilution $1: 2000)$ during the $3^{\text {rd }}$ wash after the secondary antibody treatment. Samples were imaged with Zeiss Axio Scope.A1 fluorescence microscope (Zeiss, Oberkochen, Germany).

\section{SDS-PAGE and immunoblotting}

The effect of the BaGs on the activation of FAK and MAPKs as well as the production of vinculin and integrin $\beta 1$ was analysed by SDS-PAGE and immunoblotting, as previously described (Vanhatupa et al., 2015). The target proteins were probed with the following primary antibodies: rabbit monoclonal anti-pFAK (Cell Signaling Technology, Danvers, MA, USA; dilution 1:1000), rabbit monoclonal antipERK (p-p44/42; Cell Signaling Technology; dilution 1:2000), rabbit monoclonal anti-p-p38 (Cell Signaling Technology; dilution 1:1000), rabbit polyclonal antip-c-Jun (Ser 63) (Cell Signaling Technology; dilution 1:1000), mouse monoclonal anti-integrin $\beta 1$ (Santa Cruz Biotechnology, Dallas, Texas, USA; dilution 1:500), vinculin ABfinity ${ }^{\mathrm{TM}}$ recombinant rabbit antibody (Life Technologies, Thermo Fisher Scientific; dilution 1:500) and mouse monoclonal anti- $\beta$-actin (Santa Cruz Biotechnology; dilution 1:2000), followed by horseradish peroxidase-conjugated secondary antibodies goat anti-mouse IgG (Santa Cruz Biotechnology; dilution 1:2000) and anti-rabbit IgG (Cell Signaling Technology; dilution 1:2000). Proteins were detected with enhanced chemiluminescence detection reagent (ECL; GE Healthcare) using a ChemiDoc MP imaging system (Bio-Rad, Hercules, CA, USA). To analyse the basal levels of nonphosphorylated proteins, the blots were stripped and blotted again by the following antibodies: rabbit anti-FAK (Cell Signaling Technology; dilution 1:1000), rabbit polyclonal anti-ERK2 (Santa Cruz Biotechnology; dilution 1:500), rabbit polyclonal anti-p38 $\alpha$ (Santa Cruz Biotechnology; dilution 1:100) and rabbit monoclonal anti-c-Jun (Cell Signaling Technology; dilution 1:1000).

\section{Analysis of the glass surfaces by scanning electron microscopy (SEM) and confocal white light microscopy (COM)}

To study the changes in the BaG material surfaces and in the cell morphology on BaGs during the experimental period, the discs were characterised using SEM (Leo 1530, combined with energy dispersive X-ray analysis (EDXA, UltraDry, Thermo Fisher Scientific)). At each time point samples were washed once with PBS and fixed with $5 \%$ glutaraldehyde (Sigma-Aldrich) for $1 \mathrm{~h}$ at room temperature. After fixation, samples were stored in deionised water at $+4{ }^{\circ} \mathrm{C}$ and prior to imaging they were dehydrated by ascending concentrations of ethanol, followed by air drying. For the SEM analysis of the cross-sections, the discs were cast in epoxy resin, cut in half with a diamond blade and polished first using wet polishing papers (1,000 and 2,000 grit) and finally using a fine polishing paper (2,500 grit) with ethanol, which resulted in a smooth finish for the SEM imaging. The topography and surface roughness of the polystyrene control and the pre-incubated glass discs of both S53P4 and 1-06 were characterised with COM (Nanofocus $\mu$ Surf 3D).

\section{Ionic release from the $\mathrm{BaG}$ discs}

In order to determine the ionic release profile of the $\mathrm{BaGs}$, medium samples were collected at the time of each medium change and the ion concentrations of $\mathrm{Ca}, \mathrm{P}, \mathrm{K}, \mathrm{Mg}, \mathrm{B}$ and $\mathrm{Si}$ in the culture medium were determined by inductively-coupled plasma optical 
emission spectrometry (ICP-OES; Optima 5300 DV, Perkin Elmer, Waltham, MA, USA) as previously described (Ojansivu et al., 2015).

\section{Statistical analysis}

Statistical analyses were performed with SPSS Statistics version 22 (IBM, Armonk, NY, USA). All the quantitative data is presented as mean and standard deviation. The statistical significances were evaluated using Kruskal-Wallis one-way analysis of variance by ranks, and with Mann-Whitney post hoc test combined with Bonferroni correction. These non-parametric tests were chosen because, due to the relatively small $n$, to assume the data to be normally distributed could not be justified.
The result was considered statistically significant when the adjusted $p$-value was $<0.05$.

\section{Results}

\section{Cell viability and proliferation}

As seen in Fig. 1A, adherent cells remained viable on all the materials and in the presence of all the inhibitors throughout the whole culturing period. However, some morphological changes were observed. For example, the inhibition of FAK seemed to increase the size of the cells whereas the inhibition of p38 notably decreased the cell size. With respect to cell proliferation, of the four inhibitors only FAK

A
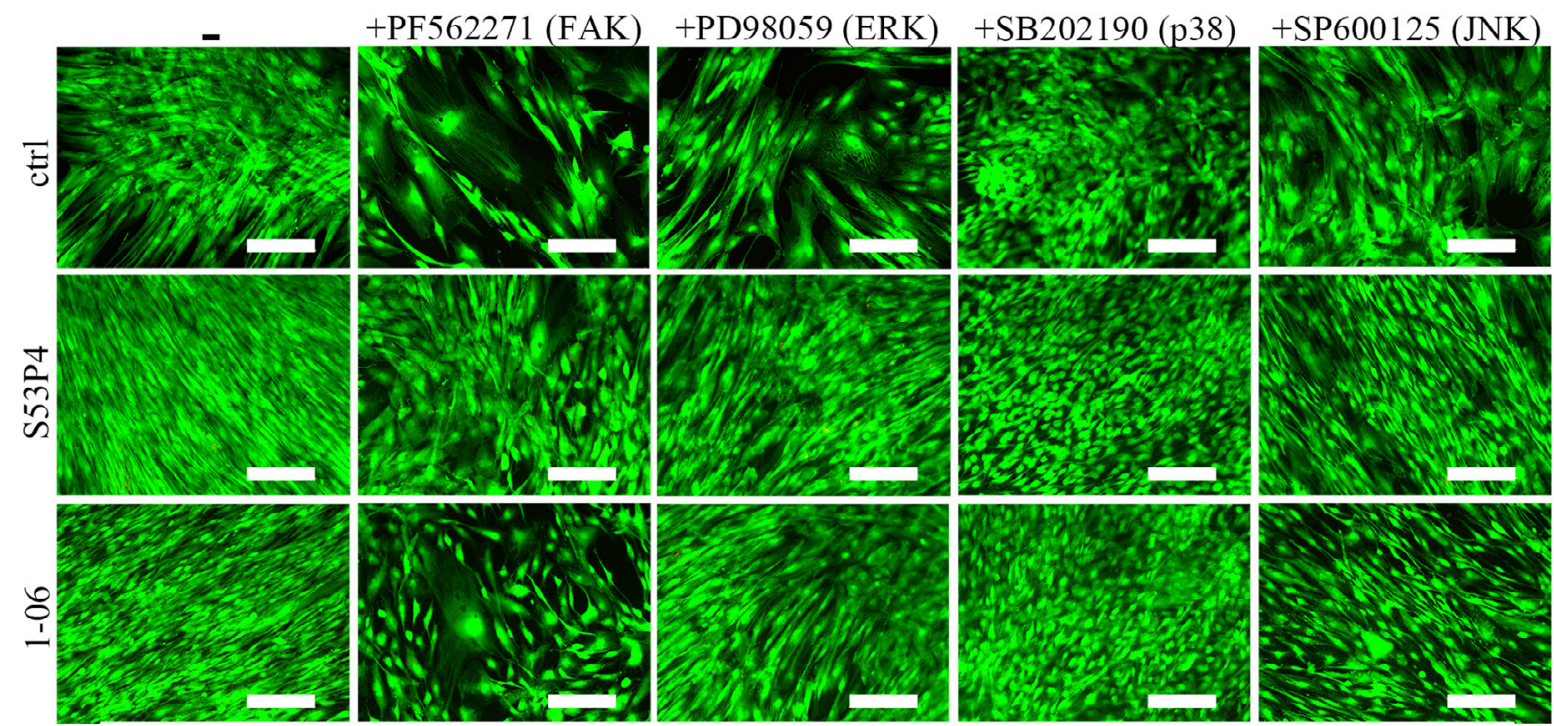

B

Cell proliferation

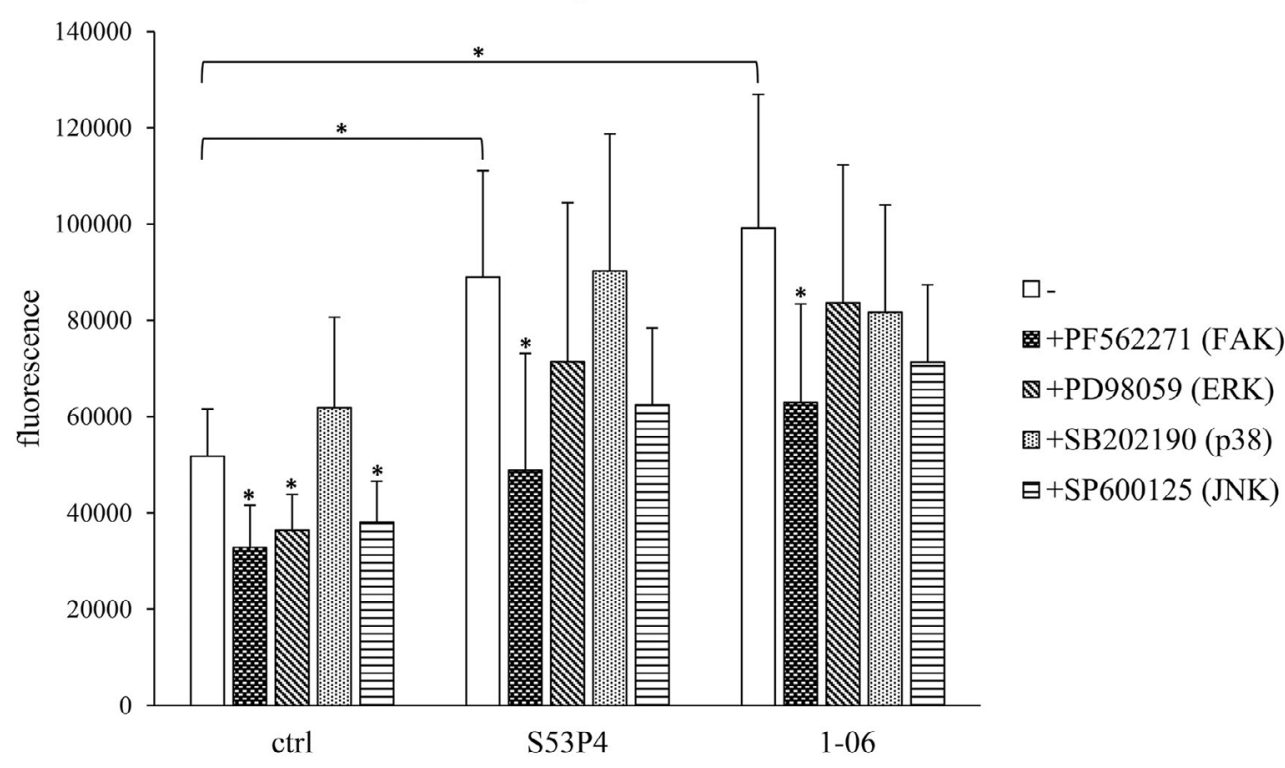

Fig. 1. The viability and proliferation of hASCs in different culturing conditions. A. The viability of hASCs at $21 \mathrm{~d}$ as determined by live/dead staining. Living cells are stained green and dead cells red. Scale bar $200 \mu \mathrm{m}$. B. Cell proliferation at $21 \mathrm{~d}$. The proliferation was analysed by a CyQUANT assay. $n=12 .{ }^{*} p<0.05$. ctrl = control (polystyrene). Concentrations of the inhibitors: PF562271 $2 \mu$ M, PD98059 $60 \mu$ M, SB202190 $2 \mu$ M, SP600125 $10 \mu \mathrm{M}$. 
inhibitor significantly decreased the cell amount on both glass types (S53P4: $p<0.001 ; 1-06: p=0.010$ ) (Fig. 1B). Still, there were a considerable number of cells even in the presence of FAK inhibitor. In the control condition on the other hand, in addition to FAK $(p=0.002)$, ERK and JNK inhibition also significantly decreased cell numbers $(p=0.006$ and $p=0.027$, respectively). Interestingly, in the absence of inhibitors, both glass types had an increasing effect on cell proliferation when compared to the polystyrene control $(p<0.001)$. Live/dead and CyQUANT analyses demonstrated that none of the culture conditions severely compromised the cell viability or proliferation, which enabled further studies with these materials and inhibitor concentrations.

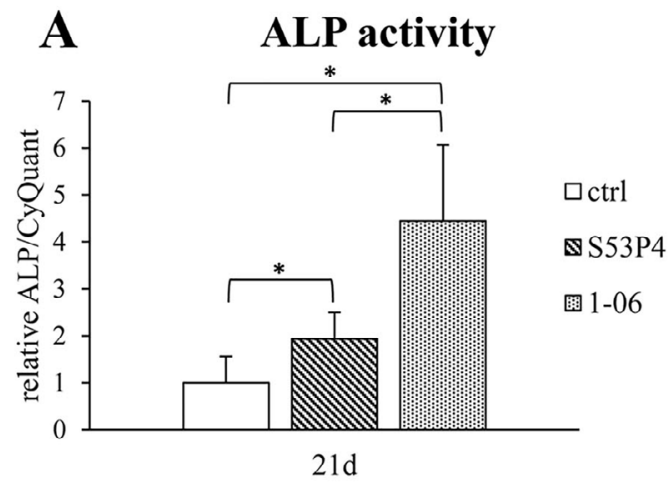

\section{B RUNX2a}

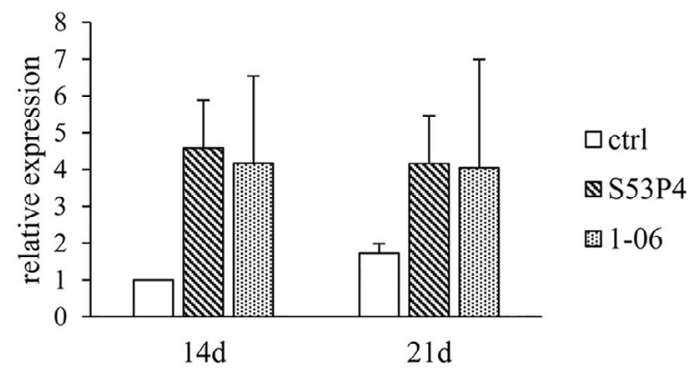

C OSTERIX

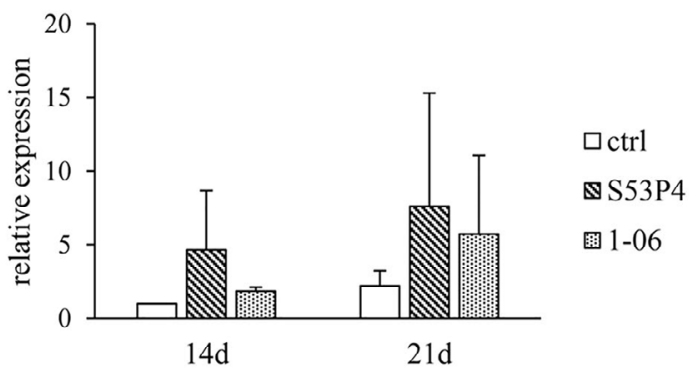

D

Fibronectin Actin cytoskeleton Nuclei
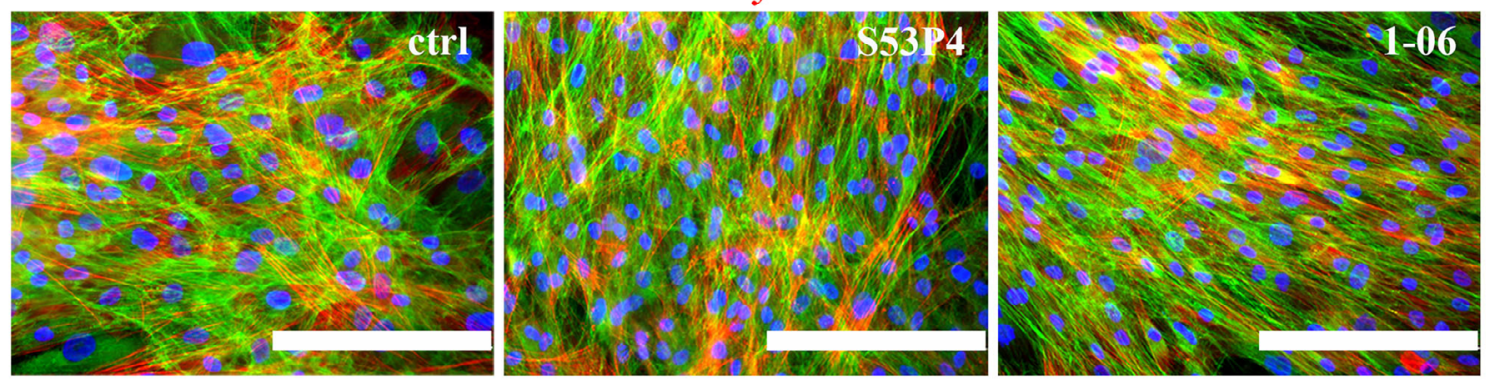

$\mathbf{E}$

Collagen-I Actin cytoskeleton Nuclei
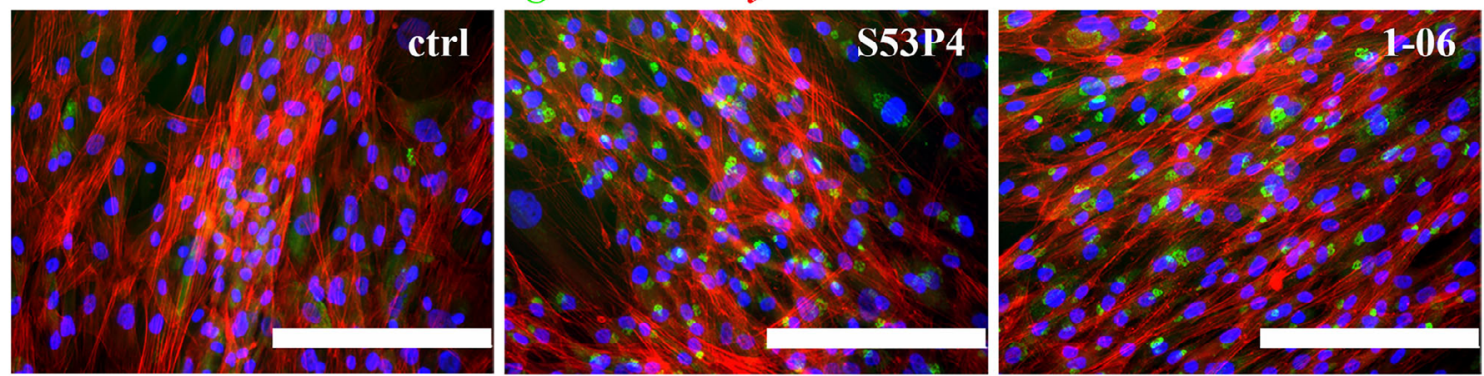

Fig. 2. Early osteogenic differentiation and ECM production of hASCs on BaGs. A. Alkaline phosphatase (ALP) activity at $21 \mathrm{~d}$ normalised with cell amount determined by CyQUANT assay. $n=12$. B. RUNX2a expression at $14 \mathrm{~d}$ and $21 \mathrm{~d} . n=4$. C. OSTERIX expression at $14 \mathrm{~d}$ and $21 \mathrm{~d} . n=4$. The results are relative to the control (ctrl; polystyrene). ${ }^{*} p<0.05$. D. ICC of fibronectin (green) at $21 \mathrm{~d}$. E. ICC of collagen-I (green) at $21 \mathrm{~d}$. Scale bars $200 \mu \mathrm{m}$. Actin cytoskeleton was stained red with phalloidin and nuclei blue with DAPI. Ctrl = control (polystyrene). 


\section{Osteogenic differentiation and ECM production} of hASCs on BaGs

As indicated in Fig. 2A, in direct culture both glass types significantly increased ALP activity at $21 \mathrm{~d}$ when compared to the control polystyrene $(p<0.001)$. Furthermore, 1-06 induced a significantly higher ALP activity than S53P4 $(p<0.001)$. Both glass types also increased the expression of RUNX2a (Fig. 2B) and OSTERIX (Fig. 2C) at $14 \mathrm{~d}$ and $21 \mathrm{~d}$, confirming their ability to induce early osteogenic differentiation of hASCs. In gene expression level, however, there were no clear differences between the two glass types. With respect to ECM production, cells produced large amounts of fibronectin, independent of the culturing material (Fig. 2D). The production of collagen-I, on the other hand, was clearly upregulated on both of the glasses when compared to the polystyrene control (Fig. 2E). However, the localisation of collagen-I was clearly intracellular, presumably in Golgi apparatus and endoplasmic reticulum close to nuclei. This indicated a dramatically enhanced pre-collagen production in hASCs cultured on the glasses.
A Vinculin Actin cytoskeleton Nuclei $24 h$
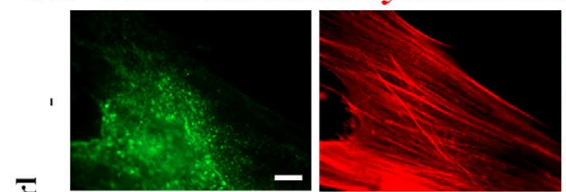

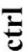
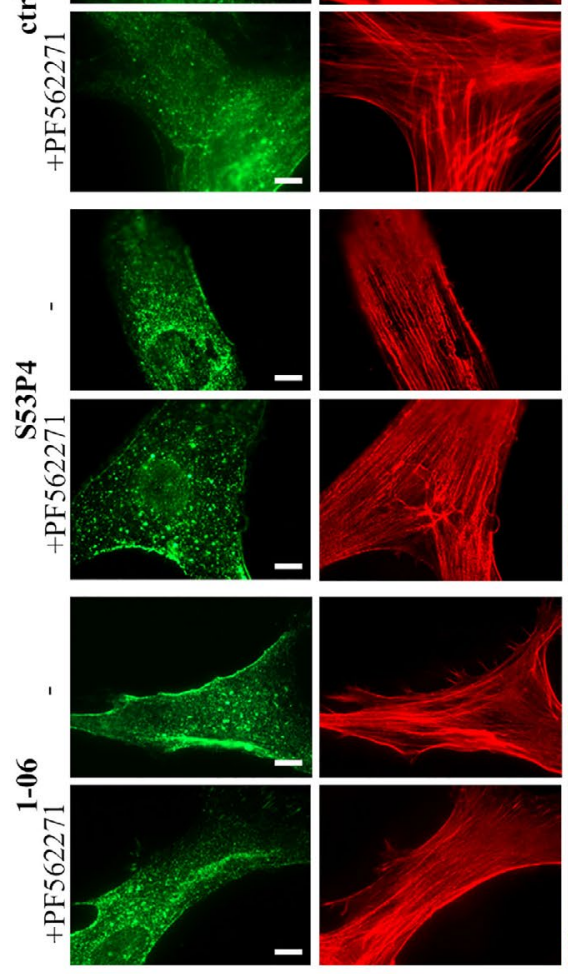

$\stackrel{\varrho}{1}$

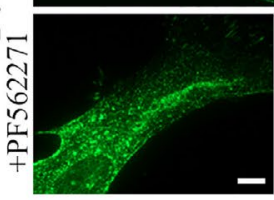

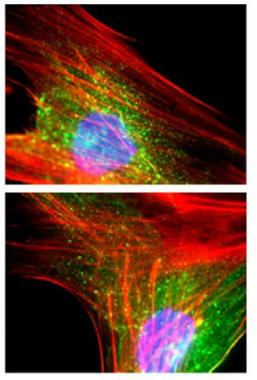
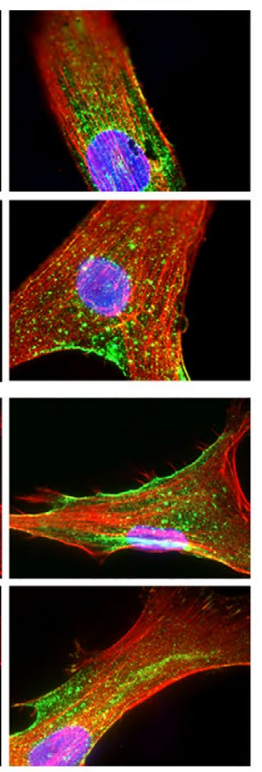

B
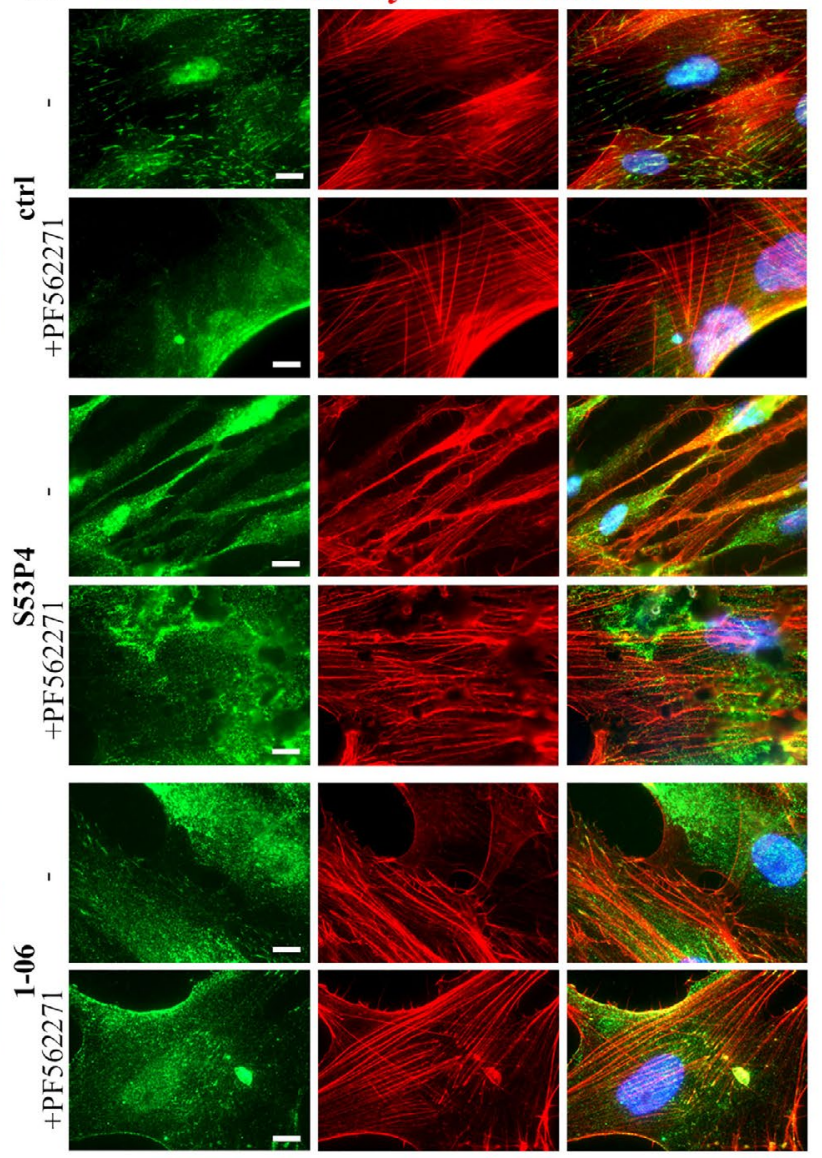

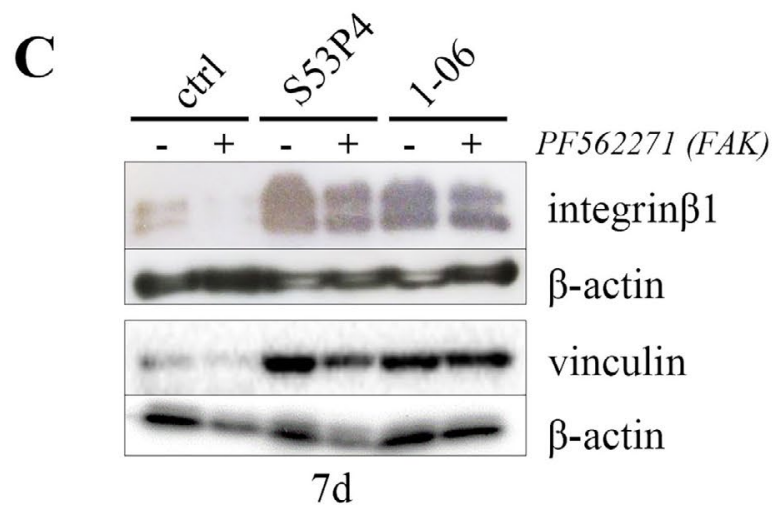

Fig. 3. Cell attachment and actin cytoskeleton on BaGs. A,B. ICC of vinculin at $24 \mathrm{~h}$ and $7 \mathrm{~d}$, respectively, in the presence or absence of FAK inhibitor PF562271 (2 $\mu \mathrm{M})$. Actin cytoskeleton was stained red with phalloidin and nuclei blue with DAPI. Scale bars $10 \mu \mathrm{m}$. ctrl = control (polystyrene). C. Western blot analysis of integrin $\beta 1$ and vinculin at $7 \mathrm{~d}$ in the presence or absence of FAK inhibitor PF562271 ( $2 \mu \mathrm{M})$. $\beta$-actin served as a loading control. 
Cell attachment and actin cytoskeleton on BaGs Immunocytochemistry of vinculin, a marker of mature focal adhesions (FA), revealed that at the $24 \mathrm{~h}$ time point no strong and clear FA sites were formed on either of the materials; instead, small adhesion sites were spread throughout the cells (Fig. 3A). At $7 \mathrm{~d}$, pronounced FAs were formed at the end of the actin fibres on control polystyrene material (Fig. 3B). However, on both of the glasses, FAs were still small and covered most of the cell area. On the glasses, the inhibition of FAK did not seem to have a notable effect on either vinculin amount or arrangement. But, on control polystyrene at $7 \mathrm{~d}$, it hindered the formation of large FA sites. The actin fibres of the cells grown on BaGs were not as stretched or aligned as the fibres of the control cells grown on polystyrene. Moreover, at some spots, the actin fibres on BaGs were even partially disorganised. The inhibition of FAK did not affect the appearance of the fibres on the glasses, but on control polystyrene it made the fibres even thicker than without the inhibitor.

In addition to the immunocytochemistry, we also evaluated the production of FA proteins integrin $\beta 1$ and vinculin by Western blot analysis (Fig. 3C). After $7 \mathrm{~d}$ of culture, the amount of both integrin $\beta 1$ and vinculin was clearly increased on both of the glasses. Interestingly, the inhibition of FAK did not seem to affect the production of these proteins.

\section{The role of FAK in the BaG-induced early osteogenic differentiation of hASCs}

In order to evaluate the role of FAK in the BaGinduced early osteogenic differentiation, ALP activity and the expression of osteogenic marker genes in the presence of FAK inhibitor were analysed. As seen in Fig. 4A, the inhibition of FAK significantly decreased the normalised ALP activity on both glasses $(p<0.001)$. A similar trend was seen in the expression of RUNX $2 a$ and OSTERIX (Fig. 4B and $4 \mathrm{C}$, respectively). Regarding the activation of FAK, Fig. 4D shows that at $3 \mathrm{~d}$ no activation of FAK could be detected on either of the materials; but at $7 \mathrm{~d}$ FAK activation was upregulated by both glass types. Interestingly, also the basal levels of FAK were increased on the glasses at both time points.

\section{The role of ERK1/2 in the BaG-induced early osteogenic differentiation of hASCs}

As with the inhibition of FAK, the inhibition of ERK1/2 significantly decreased the normalised ALP activity on both glasses $(p<0.001)$ (Fig. 5A). The same effect was seen also in the expression of osteogenic marker genes RUNX2 $a$ and OSTERIX (Fig. 5B and $5 \mathrm{C}$, respectively). When it came to ERK1/2 activation, both glasses increased the activation of ERK1/2 after $3 \mathrm{~d}$ and $7 \mathrm{~d}$ of culture (Fig. 5D). Unlike with FAK, the basal levels of ERK2 were not affected by the
A

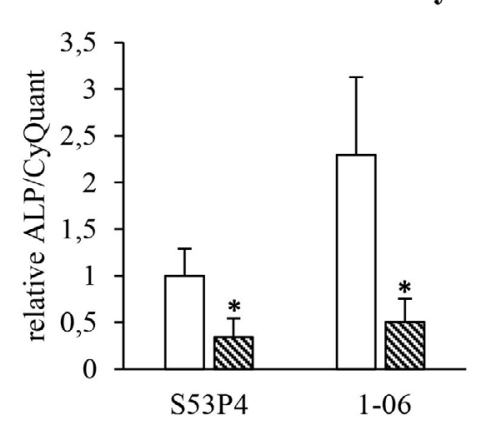

C

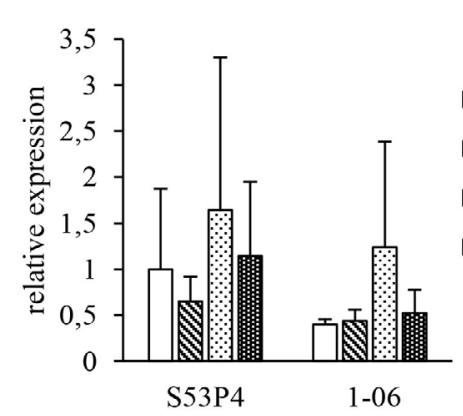

$\square-$

\$ PF562271 (FAK)

B

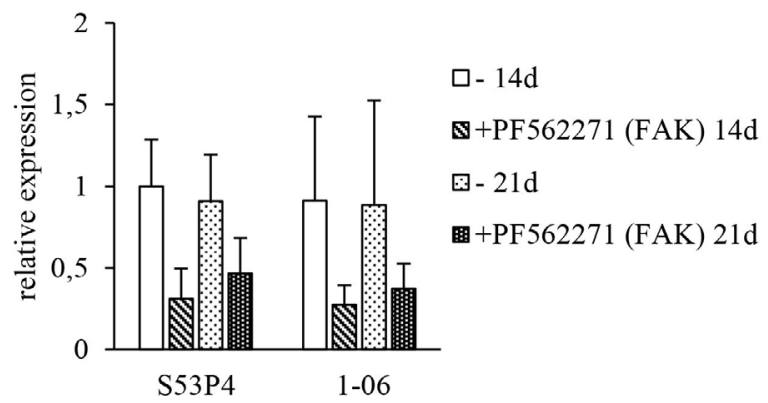

D

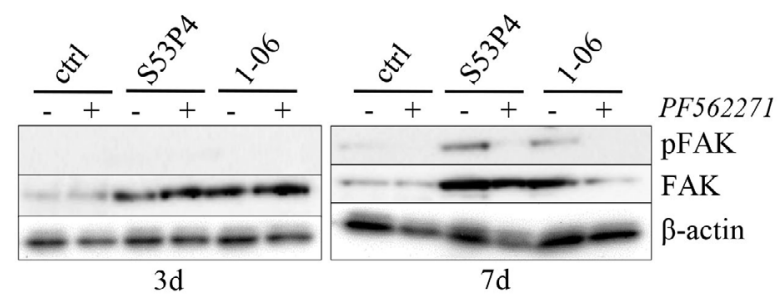

Fig. 4. The role of FAK in the BaG-induced early osteogenic differentiation of hASCs. A. Normalised ALP activity at $21 \mathrm{~d}$. The results are represented relative to the S53P4 without the inhibitor (-). $n=12$. B,C. RUNX2a and OSTERIX expression, respectively, at $14 \mathrm{~d}$ and $21 \mathrm{~d}$. The results are relative to S53P4 without the inhibitor $(-)$ at $14 \mathrm{~d} . n=4$. FAK inhibitor PF562271 $(2 \mu \mathrm{M}) .{ }^{*} p<0.05$. D. Western blot analysis of FAK activation (phosphorylation; pFAK) on the different materials at $3 \mathrm{~d}$ and $7 \mathrm{~d}$. $\beta$-actin served as a loading control. ctrl $=$ control (polystyrene). 


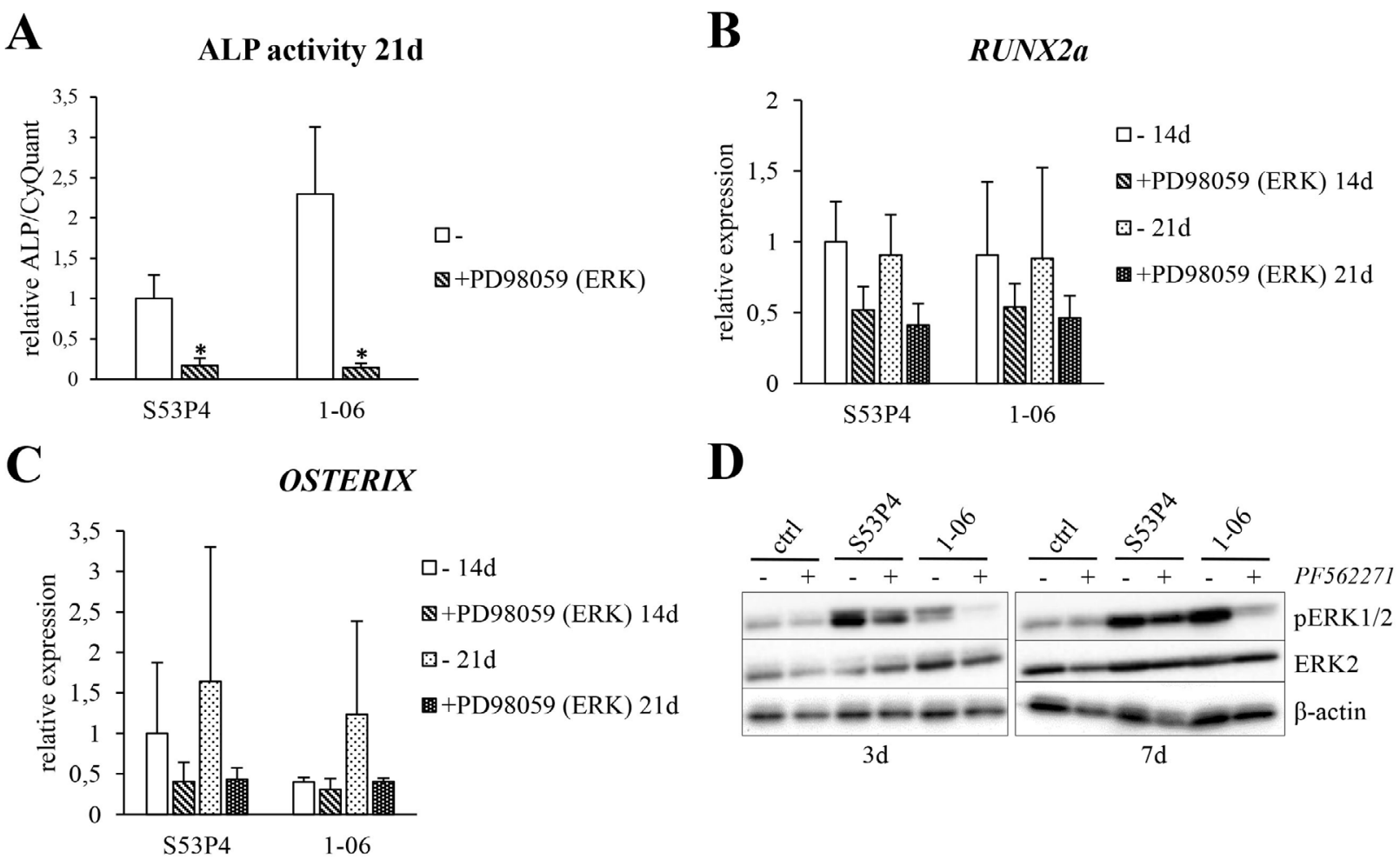

Fig. 5. The role of ERK1/2 in the BaG-induced early osteogenic differentiation of hASCs. A. Normalised ALP activity at $21 \mathrm{~d}$. The results are represented relative to the S53P4 without the inhibitor (-). $n=12$. B,C. RUNX2a and OSTERIX expression, respectively, at $14 \mathrm{~d}$ and $21 \mathrm{~d}$. The results are relative to S53P4 without the inhibitor $(-)$ at 14 d. $n=4$. ERK inhibitor PD98059 $(60 \mu \mathrm{M}) .{ }^{*} p<0.05$. D. Western blot analysis of ERK activation (phosphorylation; pERK1/2) on the different materials at $3 \mathrm{~d}$ and $7 \mathrm{~d}$. FAK inhibitor PF562271 $(2 \mu \mathrm{M}) . \beta$-actin served as a loading control. $\operatorname{ctrl}=$ control (polystyrene).

A

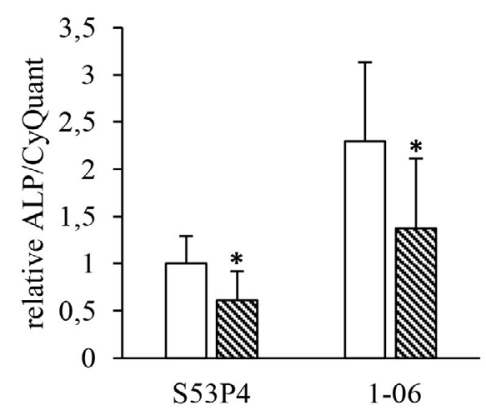

C

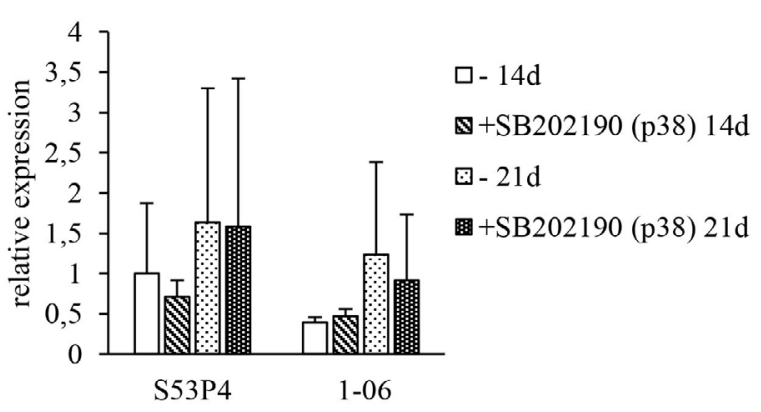

B

\section{$R U N X 2 a$}

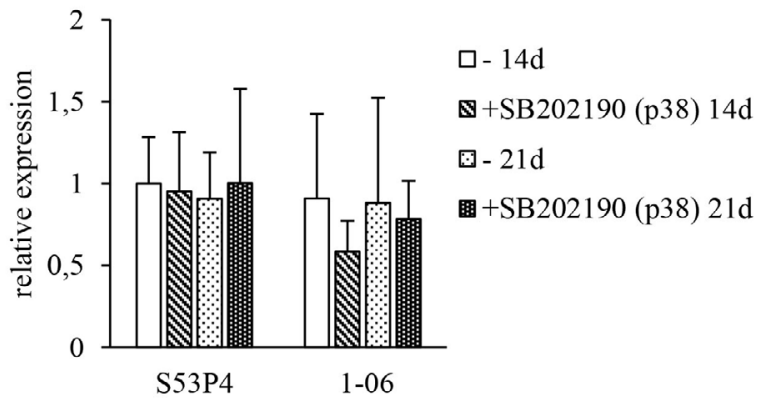

D

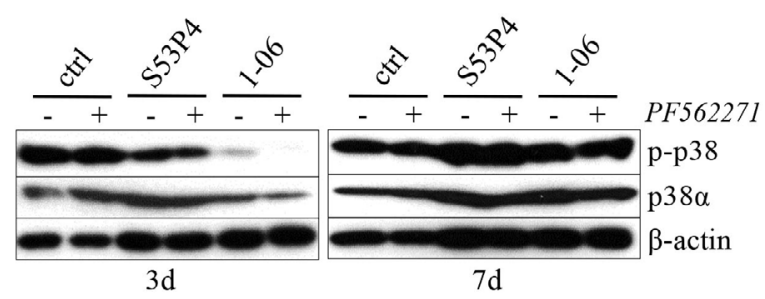

Fig. 6. The role of p38 in the BaG-induced early osteogenic differentiation of hASCs. A. Normalised ALP activity at $21 \mathrm{~d}$. The results are represented relative to the S53P4 without the inhibitor $(-) . n=12$. B,C. RUNX2 $a$ and OSTERIX expression, respectively, at $14 \mathrm{~d}$ and $21 \mathrm{~d}$. The results are relative to S53P4 without the inhibitor $(-)$ at $14 \mathrm{~d}$. $n=4$. p38 inhibitor SB202190 $(2 \mu \mathrm{M}) .{ }^{*} p<0.05$. D. Western blot analysis of p38 activation (phosphorylation; p-p38) on the different materials at $3 \mathrm{~d}$ and $7 \mathrm{~d}$. FAK inhibitor PF562271 ( $2 \mu \mathrm{M})$. $\beta$-actin served as a loading control. $\operatorname{ctrl}=\operatorname{control}$ (polystyrene). 
glasses. In the presence of FAK inhibition the activity of ERK1/2 was diminished on both glasses.

The role of p38 in the BaG-induced early osteogenic differentiation of hASCs

Similar to FAK and ERK1/2, the inhibition of p38 significantly decreased the normalised ALP activity (S53P4: $p=0.024,1-06: p=0.035$ ) (Fig. 6A) but the extent of the decrease was much smaller than with FAK and ERK1/2 inhibitors. Furthermore, on RUNX2 $a$ and OSTERIX expression the inhibition of p38 seemed to have no effect at all (Fig. 6B and 6C, respectively). With respect to the activation of $\mathrm{p} 38$, no upregulation of p38 activity was observed at either of the time points studied (Fig. 6D). On the contrary, 1-06 glass actually decreased the activation of p38 at $3 \mathrm{~d}$ and the activation was even more downregulated in the presence of FAK inhibitor.

\section{The role of JNK in the BaG-induced early} osteogenic differentiation of hASCs

When it comes to JNK, the inhibition of JNK significantly decreased the normalised ALP activity on both glass types (S53P4: $p=0.007,1-06: p<0.001$ ) (Fig. 7A) and a similar decreasing effect was also seen in the expression of RUNX2a and OSTERIX (Fig. 7B and $7 \mathrm{C}$, respectively). Since the phosphorylation levels of JNK were extremely low in all the studied conditions and time points (data not shown), the activation of c-Jun, a downstream target of JNK (Pulverer et al., 1991), was analysed in order to assess the effect of the BaGs on the JNK function. As seen in Fig. 7D, the activation of c-Jun was upregulated by both of the glasses at $3 \mathrm{~d}$ and $7 \mathrm{~d}$ time points. Unlike with ERK1/2 and p38, the inhibition of FAK had no clear effect on the c-Jun activation. Both glasses also increased the basal levels of c-Jun at all the time points studied.

\section{Characterisation of the BaG surfaces}

The cross-section SEM images of the BaG discs (Fig. 8A) showed clear reaction layer formation in S53P4 and 1-06 after immersion in the culture medium. Two distinct reaction layers were observed: a thin layer rich in calcium and phosphorous (CaP layer) formed on top of the $\mathrm{SiO}_{2}$ layer in S53P4 at $7 \mathrm{~d}$ and $21 \mathrm{~d}$, and in 1-06 at $21 \mathrm{~d}$. Both glasses reacted progressively and the reaction layer thicknesses increased from $7 \mathrm{~d}$ to $21 \mathrm{~d}$. When compared at a fixed time point, S53P4 was more reactive than $1-06$, as evidenced by the reaction layer thickness.

The submicron scale morphological features of both glasses at the $7 \mathrm{~d}$ time point are displayed in the SEM images of Fig. 8B. When compared to 1-06, the submicron scale structure of the S53P4 surface was more porous and coral-like, whereas 1-06 showed a more compact and granule-like appearance, which is also indicative of the higher reactivity of
A

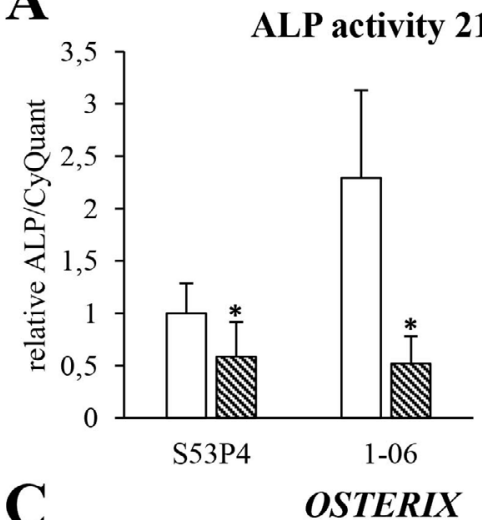

C

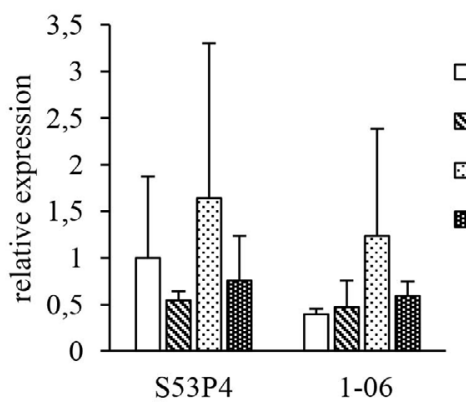

口-

$\mathrm{s}+\mathrm{SP} 600125(\mathrm{JNK})$

B

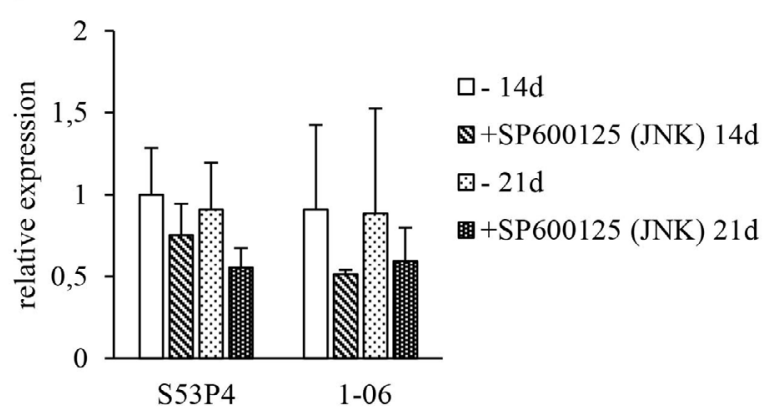

D

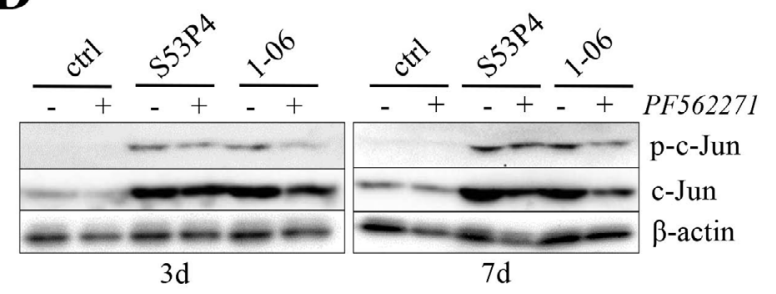

Fig. 7. The role of JNK in the BaG-induced early osteogenic differentiation of hASCs. A. Normalised ALP activity at $21 \mathrm{~d}$. The results are represented relative to the S53P4 without the inhibitor (-). $n=12$. B,C. RUNX2a and OSTERIX expression, respectively, at $14 \mathrm{~d}$ and $21 \mathrm{~d}$. The results are relative to S53P4 without the inhibitor $(-)$ at $14 \mathrm{~d}$. $n=4$. JNK inhibitor SP600125 $(10 \mu \mathrm{M}) .{ }^{*} p<0.05$. D. Western blot analysis of c-Jun activation (phosphorylation; p-c-Jun) on the different materials at $3 \mathrm{~d}$ and $7 \mathrm{~d}$. FAK inhibitor PF562271 ( $2 \mu \mathrm{M})$. $\beta$-actin served as a loading control. $\operatorname{ctrl}=$ control (polystyrene). 
A
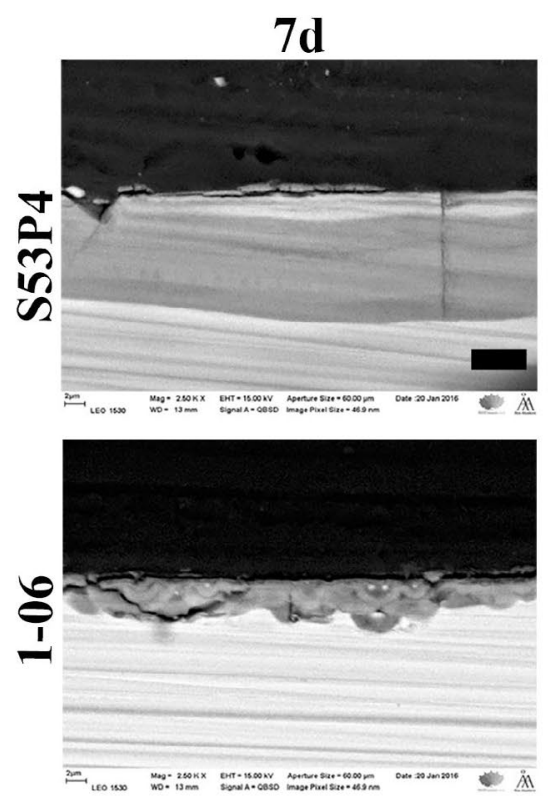

C

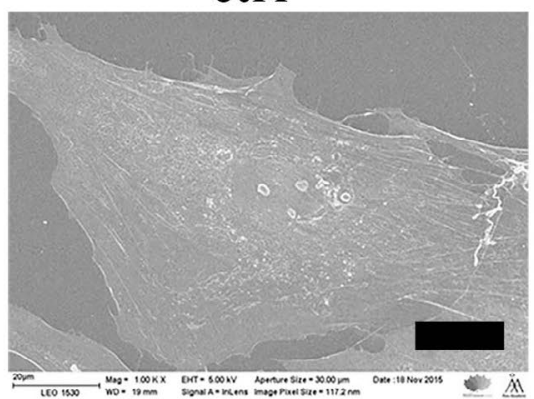

\section{1d}
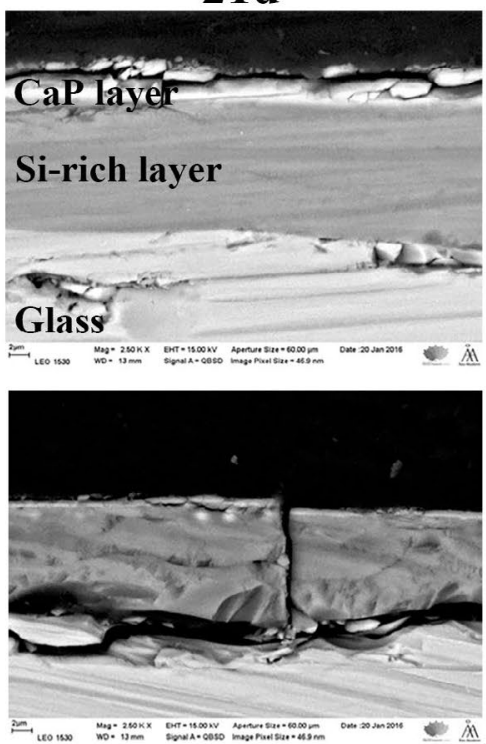

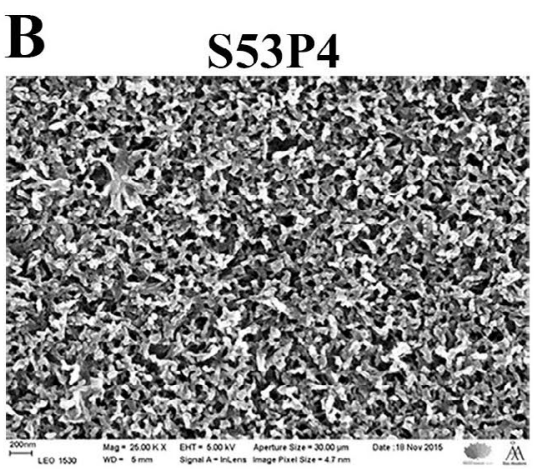

\section{1-06}

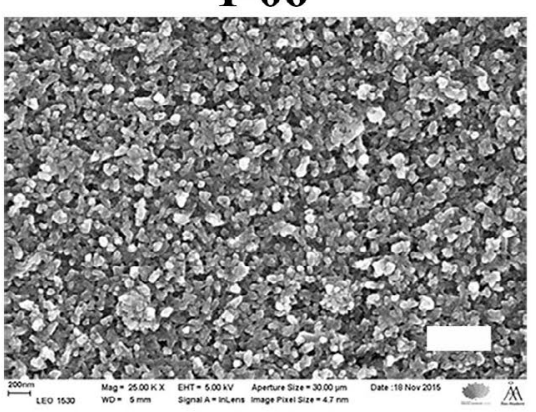

1-06
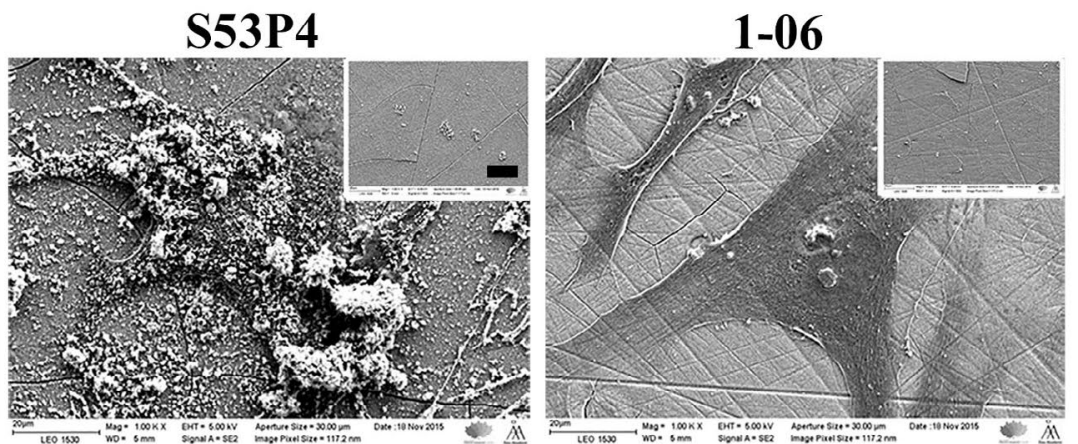
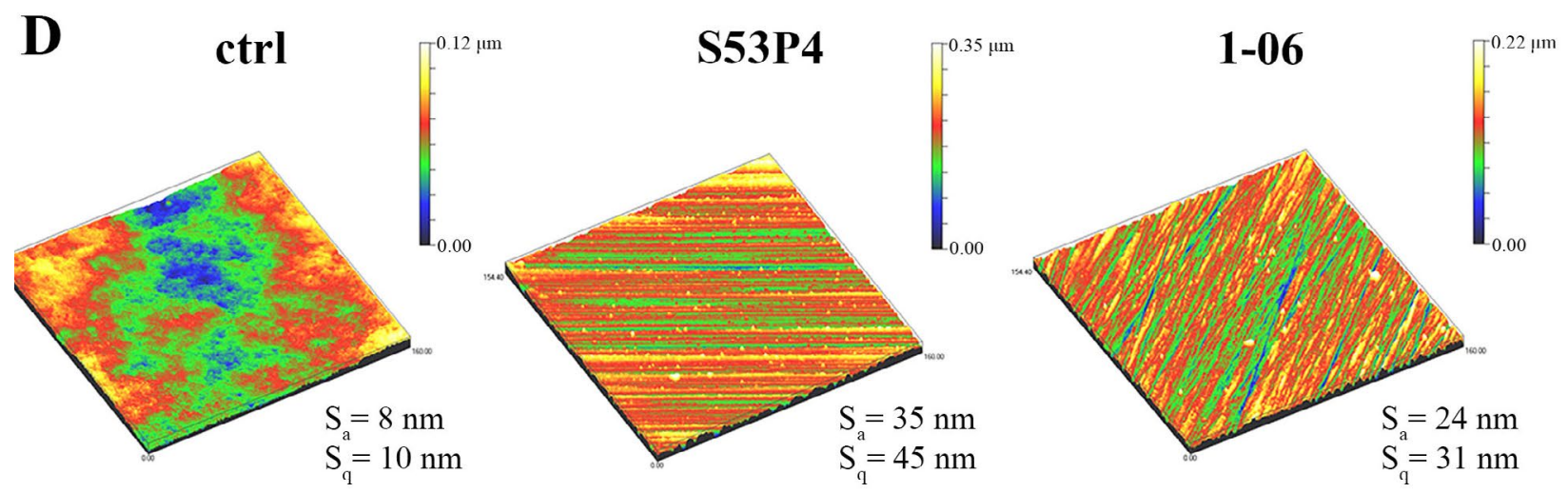

Fig. 8. Characterisation of the BaG surfaces. A. Reaction layer formation on the BaGs. The cross-sections of the BaG discs S53P4 and 1-06 were evaluated with SEM imaging. Discs were incubated in the cell culture medium for $7 \mathrm{~d}$ and $21 \mathrm{~d}$. Scale bar $5 \mu \mathrm{m}$. B. Submicron scale structures of the BaG disc surfaces at the $7 \mathrm{~d}$ time point, as visualised with SEM. Scale bar $500 \mathrm{~nm}$. C. Evaluation of the cells on the different surfaces after $7 \mathrm{~d}$ of culture, as analysed with SEM. Smaller images represent the surfaces of the blank samples. Scale bars $20 \mu \mathrm{m} . \mathrm{Ctrl}=$ control (polystyrene). D. Surface roughness of the samples. Surface roughness was analysed from blank samples after $1 \mathrm{~d}$ of immersion in cell culture medium using white light confocal optical microscopy. $\mathrm{S}_{\mathrm{a}}=$ average roughness, $\mathrm{S}_{\mathrm{q}}=$ root mean square roughness. 

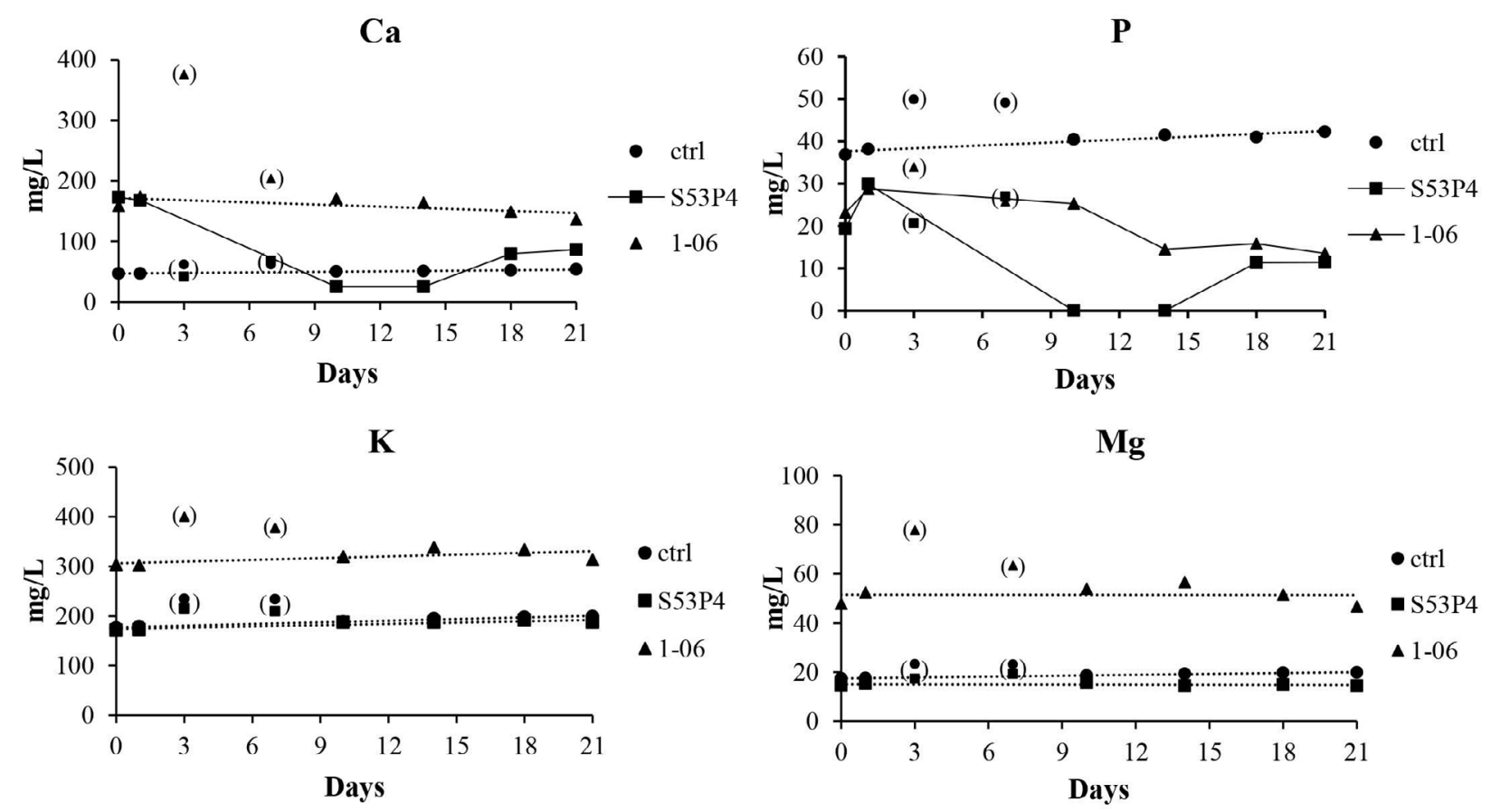

B
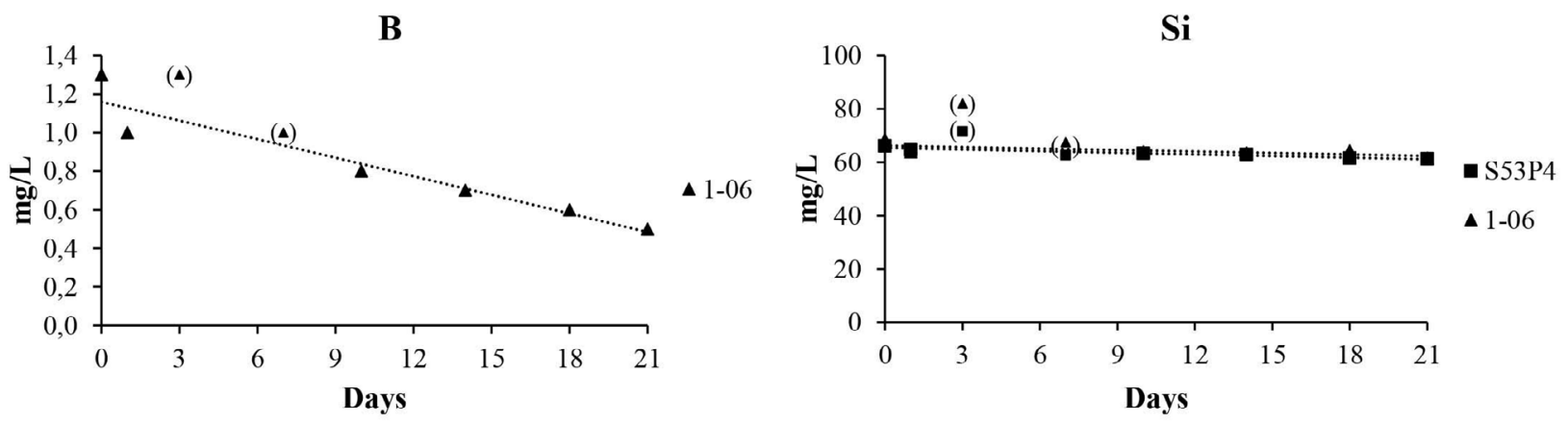

Fig. 9. Ionic release profiles of the BaG discs. Ion concentrations of $\mathrm{Ca}, \mathrm{P}, \mathrm{K}, \mathrm{Mg}, \mathrm{B}$ and $\mathrm{Si}$ were analysed with ICP-OES from medium samples collected at the time of each medium change. A linear trendline (dash line) was fitted when the release was approximately linear. In Ca and P graphs a continuous line was added to the $\mathrm{BaG}$ samples to make the temporal fluctuation in the ionic levels clearer. Measurement values of the $3 \mathrm{~d}$ and $7 \mathrm{~d}$ samples are shown in parentheses due to their systematically too high values, possibly caused by the concentration of these particular samples due to transient humidity change in the cell culture incubator. Ctrl $=$ control (polystyrene).

S53P4. In order to visualise the cells on the different surfaces, the cell-containing samples were imaged and displayed at lower magnifications with SEM at $7 \mathrm{~d}$ (Fig. 8C). The cells adopted a less flat appearance on the glasses when compared to the polystyrene control, but they were still equally spread on all the surfaces. Notably, the cells attached on S53P4 glass were covered with a precipitate of $\mathrm{CaP}$ formed in the glass dissolution. Such a precipitate was not observed on the cells on 1-06 glass. Both S53P4 and 1-06 glass discs (after the pre-incubation) showed rougher topographical features than the polystyrene control, as indicated by the surface roughness values displayed in Fig. 8D.

\section{Ionic release of the BaGs in the cell culture} medium

Fig. 9 shows the ion concentrations of $\mathrm{Ca}, \mathrm{P}, \mathrm{K}, \mathrm{Mg}$, $\mathrm{B}$ and $\mathrm{Si}$ in the culture medium at different time points for both S53P4 and 1-06 glasses, as well as for the control medium. The release of Si reached saturation during the pre-incubation of the glasses and the concentration of Si kept constant throughout the cell culture period for both S53P4 and 1-06. In control sample, no Si was detected. With respect to the dissolution of $\mathrm{Ca}$ and $\mathrm{P}$, a more profound depletion of $\mathrm{Ca}$ and $\mathrm{P}$ concentrations was seen in the S53P4 samples than in the 1-06 samples. These elements were consumed in the CaP layer formation as evidenced with the heavy $\mathrm{CaP}$ precipitate on the hASCs on S53P4 glass (Fig. 8C) and with the formation of a $\mathrm{CaP}$ layer visible in the cross-section images of S53P4 discs (Fig. 8A). In 1-06 samples, the concentrations of $\mathrm{K}$ and $\mathrm{Mg}$ reached an approximately constant level of 300 and $50 \mathrm{mg} / \mathrm{L}$ after the $24 \mathrm{~h}$ pre-incubation $(0 \mathrm{~d})$, respectively. Boron was only detected in 1-06 samples and the concentration of this element was generally relatively low $(<2 \mathrm{mg} / \mathrm{L})$. 
The effect of the released $\mathrm{BaG}$ ions on early osteogenic differentiation and signalling of hASCs

Bioactive glasses are reactive materials, which release ions upon medium immersion, and these ions are known to affect cellular behaviour (Hoppe et al., 2011). As analysed by the ICP-OES analysis, clear fluctuations in the ionic concentrations of the culture medium were also detected during the culturing period, which prompted an evaluation of whether these ions could be responsible for the observed changes in early osteogenic differentiation and cellular signalling induced by the BaGs. For this, BaG discs were placed into cell culture inserts and thus exposed cells to the glass ions without any direct glass contact. Based on these results, the ions alone could not stimulate the ALP activity (Fig. 10A) or the expression of osteogenic markers RUNX2a and OSTERIX (Fig. 10B and 10C, respectively) when compared to the control sample. Moreover, no clear effects were observed on the signalling level either, as evidenced by the lack of increased integrin $\beta 1$ production and ERK1/2 activation in insert cultures (Fig. 10D). Thus, the released BaG ions alone could not alter the osteogenic differentiation fate or the signalling status of hASCs.

\section{Discussion}

Bioactive glasses are widely studied biomaterials with a long history in biomedical research and clinical applications. However, despite the vast amount of research conducted with BaGs, very little knowledge exists relating to the molecular level effects of these materials on cells. A comprehensive understanding of the biological impact of the BaGs at the cellular level would significantly improve the design and use of BaGs in demanding TE applications. S53P4 has proved to be a relevant $\mathrm{BaG}$ type for clinical bone $\mathrm{TE}$, and in combination with hASCs has brought highly encouraging results in the treatment of craniomaxillofacial bone defects (Sandor et al., 2014). This fact prompted an examination of the biological signalling response of hASC cultured on S53P4 and, as a comparison, on an experimental BaG 1-06.

As expected, based on a previous study (Waselau et al., 2012), S53P4 glass induced early osteogenic differentiation of hASCs as determined by ALP activity, RUNX2a and OSTERIX expression as well as collagen-I production. Interestingly, 1-06 induced a significantly higher ALP activity than S53P4, implying that this experimental glass is a more effective inducer of early osteogenic differentiation.

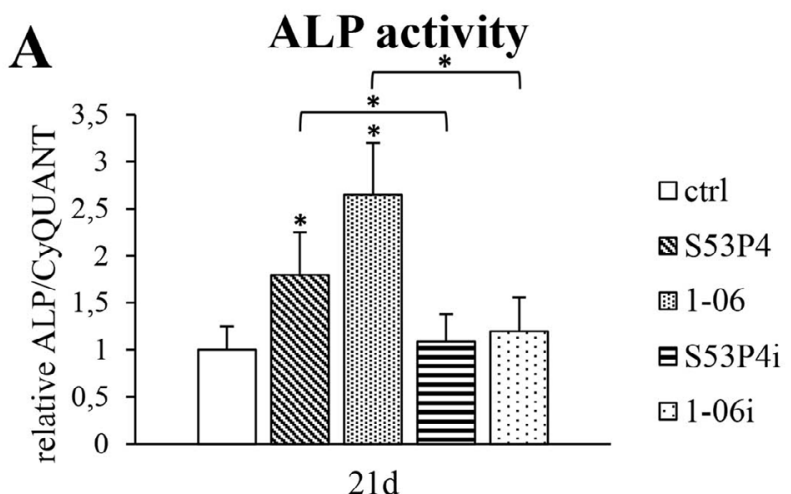

B

RUNX2a

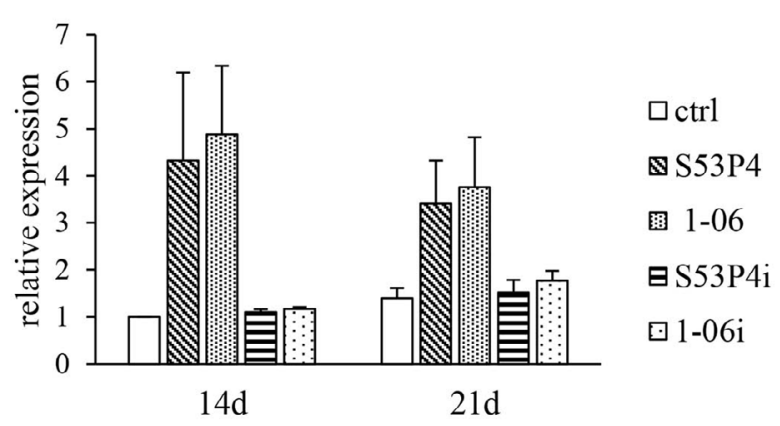

D

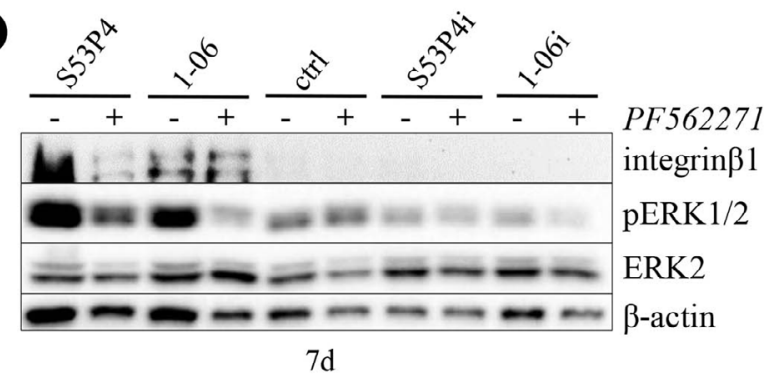

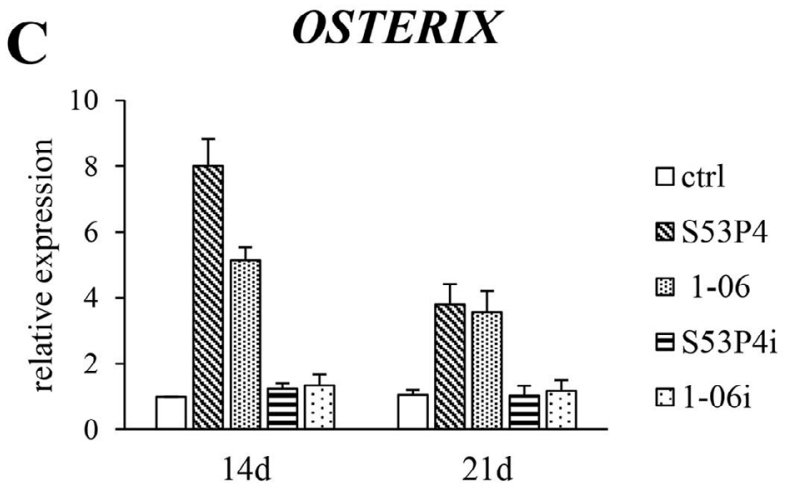

Fig. 10. The effect of ions dissolved from the BaGs on the glass-induced early osteogenic differentiation and signalling of hASCs. A. Normalised ALP activity at $21 \mathrm{~d}$. The results are represented relative to control (ctrl). $n=9 .{ }^{*} p<0.05$ (between the marked group and control, unless otherwise indicated). B,C. RUNX2a and OSTERIX expression, respectively, at $14 \mathrm{~d}$ and $21 \mathrm{~d}$. The results are relative to control (ctrl) at $14 \mathrm{~d}$. $n=3$. D. Western blot analysis of integrin $\beta 1$, pERK1/2 and ERK2 in different growth conditions at $7 \mathrm{~d}$. FAK inhibitor PF562271 $(2 \mu \mathrm{M})$. $\beta$-actin served as a loading control. ctrl = control (polystyrene). $\mathrm{i}=\mathrm{insert}$ (cells were cultured in the presence of BaG ions (glass discs in inserts) but not in direct contact with them). 
This might be explained by the structure of the material surface, which differed between the glasses due to differences in reactivity. S53P4 reacted more rapidly than 1-06 in the cell culture medium, which resulted in thicker reaction layers and a thick $\mathrm{CaP}$ precipitate overlying the cells on S53P4 glass after $7 \mathrm{~d}$ of culture. The precipitate covering the cells might have a negative effect on their differentiation.

Cells adhere to the growth substrate by means of FAs, which, upon maturation, are characterised by the presence of vinculin (Burridge and ChrzanowskaWodnicka, 1996). Surfaces that induce the formation of prominent FAs support osteogenic differentiation of stem and progenitor cells, whereas small and evenly spread FAs are linked to a decrease in osteogenic and an increase in adipogenic commitment (Abagnale et al., 2015; Biggs et al., 2009; Kilian et al., 2010). In contrast to these studies, conducted with various surface topographies and micropatterns created in polystyrene and polyimide, the results presented here indicated that the mature FAs of hASCs on S53P4 and 1-06 were small and evenly dispersed despite the evident osteogenic potential of both BaG types. It is therefore likely that the size and distribution of the FAs, as such, did not exclusively dictate cell fate. Furthermore, the amount of both integrin $\beta 1$ and vinculin increased on the glasses, suggesting that even though the FAs were small, the vast number of them might make the attachment considerably stronger. BaG surface is a continuously changing platform for the cells, due to the degradation properties of the BaGs. This unstable surface might stress cells to produce enhanced levels of cell attachment proteins and structures inside the cell, to stabilise the living conditions. Moreover, $\mathrm{BaG}$ reactivity was also related to the surface roughness, which was clearly greater on the BaGs when compared to the polystyrene. Utilising a platinum surface, the surface roughness is also linked to a decrease in FA size in fibroblasts (Pennisi et al., 2011), suggesting that the roughness of the BaGs might be also one underlying factor explaining the small FAs on the glasses.

The FAs are tightly connected to the underlying actin cytoskeleton, which changes dynamically in response to FA-mediated forces and thus regulates cell behaviour (Di Cio and Gautrot, 2015). During osteogenic differentiation, actin cytoskeleton typically turns from organised parallel actin fibres to a robust network of reorganised stress fibres with a more random patterning (Rodriguez et al., 2004; Yourek et al., 2007). In line with the observed osteogenic differentiation, a reorganised actin network was observed on both of the glasses whereas on control polystyrene the actin cytoskeleton was still more organised. At some spots, the actin fibres on BaGs seemed even slightly disorganised; but this might be due to the rapid cytoskeletal changes associated with osteogenic differentiation. Rodriguez and co-workers show that actin integrity is important at the initial steps of differentiation, but later on rapid changes occur in actin monomer/polymer equilibrium enabling the cytoskeletal reorganisation (Rodriguez et al., 2004). Sen and co-workers also suggest that disruption of the actin cytoskeleton with cytochalasin $\mathrm{D}$ is linked to an increased osteogenic differentiation of mice MSCs (Sen et al., 2015; Sen et al., 2017), thus supporting our observation of slightly disorganised actin cytoskeleton on osteoinductive BaGs. It is possible that the reactivity of the glass surfaces was transmitted to the cytoskeletal organisation via the atypical FA sites and therefore partly explained the actin arrangement.

FAK mediates messages from the cell attachment site to the interior of the cell, thus affecting cell behavior in response to cell attachment (Chatzizacharias et al., 2008; Schaller, 2001; Schlaepfer et al., 1999). It was observed that FAK was activated on both of the glasses and the inhibition of FAK significantly decreased the BaG-induced early osteogenic differentiation. These observations were well in line with the previous studies highlighting the crucial role of FAK in cell attachment related osteogenic differentiation on other types of biomaterial surfaces (Salasznyk et al., 2007a; Salasznyk et al., 2007b; Shih et al., 2011; Takeuchi et al., 1997; Viale-Bouroncle et al., 2014a; Viale-Bouroncle et al., 2014b). It seems plausible that the abundance of the FA sites on the glasses was reflected in the enhanced attachment-mediated signalling including FAK activation.

Although generally considered to be activated mainly by mitogenic stimuli (Rubinfeld and Seger, 2005), ERK1/2 is also known to be strongly related to osteogenic differentiation (Greenblatt et al., 2013). Similar to FAK, it was observed that both BaGs stimulated the activation of ERK1/2 and, upon ERK1/2 inhibition, the BaG-induced early osteogenic differentiation was greatly diminished. As expected, based on previous studies (Salasznyk et al., 2007a; Salasznyk et al., 2007b; Shih et al., 2011; Takeuchi et al., 1997; Viale-Bouroncle et al., 2014a; Viale-Bouroncle et al., 2014b), the inhibition of FAK negatively affected the ERK1/2 activation on BaGs, suggesting that ERK1/2 acted downstream of FAK also in the BaG-induced osteogenic differentiation. However, the inhibition of FAK could not totally abolish the activation of ERK1/2 implying that there are also attachment-independent stimuli acting via ERK1/2, as expected from the well-established role of ERK1/2 in mitogen signalling.

p38 and JNK are typically thought to be activated mainly by cytokines and various environmental stresses but there is also evidence that they play a role as regulators of osteogenic differentiation (Chiu et al., 2014; Gu et al., 2015; Ivaska et al., 1999; Suzuki et al., 2002; Tominaga et al., 2005). The activation of JNK downstream target c-Jun was observed in response to both BaGs. Furthermore, the early osteogenic differentiation of hASCs on BaGs was significantly decreased after treatment with JNK inhibitor, implying to a significant role for JNK in the BaG-induced osteogenesis. However, the levels of p-c-Jun were not clearly affected by the 
FAK inhibition, suggesting that JNK activation is stimulated by mechanisms not related to the FAK activation. With respect to p38, no BaG-induced activation was observed and even though the ALP was significantly decreased upon p38 inhibition, the magnitude of the decrease was lower than with the other inhibitors. Furthermore, in RUNX2a and OSTERIX gene expression levels, no changes were detected in response to p38 inhibition. Although several studies suggest an important role for p38 in both cell attachment and chemical stimuli induced osteogenesis (Ivaska et al., 1999; Suzuki et al., 2002; Tominaga et al., 2005), there are also studies, which do not demonstrate any role for p38 in the osteogenic differentiation of mesenchymal stem cells (Fu et al., 2008; Kilian et al., 2010). Thus, the role of p38 in the BaG-induced osteogenic differentiation might not simply be as significant as that of FAK, ERK1/2 and JNK.

Upon immersion into medium, BaGs release a cocktail of ions that are known to stimulate osteogenic differentiation of progenitor cells even without any added osteogenic supplements (Gong et al., 2014; Jell et al., 2008; Tsigkou et al., 2009). Since elevated levels of several ions were observed during the culturing period, it was relevant to ask whether the observed cellular changes could be caused by the glass ions instead of the attachment-related mechanisms. To shed light on this a cell culture insert-based experimental setup was built up, which enabled cell exposure to the ions released from $\mathrm{BaG}$ discs without a direct cell-biomaterial contact. Using this setup both the early osteogenic differentiation and cell signalling events were evaluated. However, no ion-induced alterations were observed in either early osteogenic differentiation or cell signalling. This was well in line with our previous study indicating that, in the absence of cell-biomaterial contact, $\mathrm{BaG}$ ions can only stimulate osteogenesis when combined with the osteogenesis-inducing chemical supplements ( $\beta$-glycerophosphate, L-ascorbic acid and dexamethasone) (Ojansivu et al., 2015). Thus, the BaG-induced early osteogenic differentiation and signalling changes observed were clearly related to the cell attachment on BaG surface or, alternatively, to a combined effect of the glass surface and released ions, but could not be explained solely by the glass dissolution products.

Thus far, despite the vast number of in vitro, in vivo and clinical studies conducted with various types of $\mathrm{BaGs}$, there is very little evidence of any effort being made to elucidate the molecular level mechanisms behind the BaG-induced cellular responses. Due to the lack of understanding of this crucial area, we were determined to shed light on the cell attachment and signalling on two silicate-BaGs, a clinically available S53P4 and an experimental glass composition 1-06. It was shown for the first time, that $\mathrm{BaG}$ s had a very profound effect on cell attachment mechanisms and the signalling cascades downstream of the attachment sites. As hypothesised, FAK and MAPKs seemed to have crucial roles in the BaG-induced early osteogenic commitment of hASCs. In general, a thorough understanding of the molecular level cell mechanisms in response to various biomaterials used in TE would improve the safety of the clinical treatments (e.g. detection of cancer-related signalling activation) and greatly facilitate a more systematic design approach of novel functional biomaterials and TE constructs. As an example, knowledge of the essential signalling cascades regulating the differentiation fate could eventually lead to a greatly enhanced differentiation induction by using appropriate inhibitor and activator molecules of these cascades. This study gave some important insights to the mechanisms of BaG-induced osteogenic commitment and thus set the basis for further characterisation of these complex signalling networks responsible for the biomaterialinduced cell behaviour and, ultimately, for the success of the TE-based clinical treatments. Thorough understanding of the BaG biological impact is highly important since it will greatly facilitate the design of novel BaG compositions and structures to meet the increasing demand for effective bone TE treatments.

\section{Conclusions}

The osteogenic differentiation of hASCs was stimulated in direct culture by both S53P4 and 1-06 BaGs, of which the less reactive 1-06 was the stronger inducer. With respect to the cell attachment, the production of integrin $\beta 1$ and vinculin was upregulated on both glasses, implying stronger attachment mechanisms of the cells to BaGs when compared to polystyrene control. The FAs on BaGs, however, were exceptionally small and spread throughout the cells, possibly related to the glass surface roughness and reactivity. FAK, ERK1/2 and JNK turned out to be essential molecules in the BaGinduced early osteogenic differentiation, whereas the role of p38 was less significant. Ions released from the $\mathrm{BaG}$ discs could not reproduce the observed cellular changes, which highlighted the role of the cell attachment in cell-BaG interaction. This was the first study analysing the molecular responses of cells on BaGs S53P4 and 1-06 and thus gave a valuable insight into the mechanism of BaG-induced early osteogenic differentiation. Such knowledge should aid the future design of new functional biomaterials for bone TE.

\section{Acknowledgements}

The authors want to thank Mrs. Sari Kalliokoski, Ms. Miia Juntunen, Ms. Anna-Maija Honkala and Mrs. Mira Partala, as well as Tampere Imaging Facility (BioMediTech and Faculty of Medicine and Life Sciences, University of Tampere), for technical assistance. The work was supported by TEKES, the Finnish Funding Agency for Innovation, Academy of Finland, Jane and Aatos Erkko Foundation, the 
Competitive State Research Financing of the Expert Responsibility area of Tampere University Hospital, and the Doctoral Programme in Biomedicine and Biotechnology, University of Tampere. The authors report no conflict of interest.

\section{References}

Abagnale G, Steger M, Nguyen VH, Hersch N, Sechi A, Joussen S, Denecke B, Merkel R, Hoffmann B, Dreser A, Schnakenberg U, Gillner A, Wagner W (2015) Surface topography enhances differentiation of mesenchymal stem cells towards osteogenic and adipogenic lineages. Biomaterials 61: 316-326.

Au AY, Au RY, Demko JL, McLaughlin RM, Eves BE, Frondoza CG (2010) Consil bioactive glass particles enhance osteoblast proliferation and selectively modulate cell signaling pathways in vitro. J Biomed Mater Res A 94: 380-388.

Biggs MJ, Richards RG, Gadegaard N, McMurray RJ, Affrossman S, Wilkinson CD, Oreffo RO, Dalby MJ (2009) Interactions with nanoscale topography: adhesion quantification and signal transduction in cells of osteogenic and multipotent lineage. J Biomed Mater Res A 91: 195-208.

Burridge K, Chrzanowska-Wodnicka M (1996) Focal adhesions, contractility, and signaling. Annu Rev Cell Dev Biol 12: 463-518.

Chatzizacharias NA, Kouraklis GP, Theocharis SE (2008) Disruption of FAK signaling: a side mechanism in cytotoxicity. Toxicology 245: 1-10.

Chiu LH, Lai WF, Chang SF, Wong CC, Fan CY, Fang CL, Tsai YH (2014) The effect of type II collagen on MSC osteogenic differentiation and bone defect repair. Biomaterials 35: 2680-2691.

Detsch R, Alles S, Hum J, Westenberger P, Sieker F, Heusinger D, Kasper C, Boccaccini AR (2015) Osteogenic differentiation of umbilical cord and adipose derived stem cells onto highly porous 45S5 Bioglass(R)-based scaffolds. J Biomed Mater Res A 103: 1029-1037.

Di Cio S, Gautrot JE (2015) Cell sensing of physical properties at the nanoscale: Mechanisms and control of cell adhesion and phenotype. Acta Biomater 30: 26-48.

Fu L, Tang T, Miao Y, Zhang S, Qu Z, Dai K (2008) Stimulation of osteogenic differentiation and inhibition of adipogenic differentiation in bone marrow stromal cells by alendronate via ERK and JNK activation. Bone 43: 40-47.

Gong W, Huang Z, Dong Y, Gan Y, Li S, Gao $X$, Chen X (2014) Ionic extraction of a novel nanosized bioactive glass enhances differentiation and mineralization of human dental pulp cells. J Endod 40: 83-88.

Greenblatt MB, Shim JH, Glimcher LH (2013) Mitogen-activated protein kinase pathways in osteoblasts. Annu Rev Cell Dev Biol 29: 63-79.

Gu H, Huang Z, Yin X, Zhang J, Gong L, Chen J, Rong K, Xu J, Lu L, Cui L (2015) Role of
c-Jun N-terminal kinase in the osteogenic and adipogenic differentiation of human adipose-derived mesenchymal stem cells. Exp Cell Res 339: 112-121.

Haimi S, Gorianc G, Moimas L, Lindroos B, Huhtala H, Raty S, Kuokkanen H, Sandor GK, Schmid C, Miettinen S, Suuronen R (2009a) Characterization of zinc-releasing three-dimensional bioactive glass scaffolds and their effect on human adipose stem cell proliferation and osteogenic differentiation. Acta Biomater 5: 3122-3131.

Haimi S, Moimas L, Pirhonen E, Lindroos B, Huhtala H, Räty S, Kuokkanen H, Sandor GK, Miettinen S, Suuronen R (2009b) Calcium phosphate surface treatment of bioactive glass causes a delay in early osteogenic differentiation of adipose stem cells. J Biomed Mater Res A 91: 540-547.

Hoppe A, Guldal NS, Boccaccini AR (2011) A review of the biological response to ionic dissolution products from bioactive glasses and glass-ceramics. Biomaterials 32: 2757-2774.

Hynes RO (2002) Integrins: bidirectional, allosteric signaling machines. Cell 110: 673-687.

Ivaska J, Reunanen H, Westermarck J, Koivisto L, Kähäri VM, Heino J (1999) Integrin alpha2beta1 mediates isoform-specific activation of p38 and upregulation of collagen gene transcription by a mechanism involving the alpha2 cytoplasmic tail. J Cell Biol 147: 401-416.

Jaiswal RK, Jaiswal N, Bruder SP, Mbalaviele G, Marshak DR, Pittenger MF (2000) Adult human mesenchymal stem cell differentiation to the osteogenic or adipogenic lineage is regulated by mitogen-activated protein kinase. J Biol Chem 275: 9645-9652.

Jell G, Notingher I, Tsigkou O, Notingher P, Polak JM, Hench LL, Stevens MM (2008) Bioactive glassinduced osteoblast differentiation: a noninvasive spectroscopic study. J Biomed Mater Res A 86: 31-40.

Jones JR (2013) Review of bioactive glass: From Hench to hybrids. Acta Biomater 9: 4457-4486.

Kilian KA, Bugarija B, Lahn BT, Mrksich M (2010) Geometric cues for directing the differentiation of mesenchymal stem cells. Proc Natl Acad Sci U S A 107: 4872-4877.

Kim GH, Park YD, Lee SY, El-Fiqi A, Kim JJ, Lee EJ, Kim HW, Kim EC (2015) Odontogenic stimulation of human dental pulp cells with bioactive nanocomposite fiber. J Biomater Appl 29: 854-866.

Kyllönen L, Haimi S, Mannerström B, Huhtala H, Rajala KM, Skottman H, Sandor GK, Miettinen S (2013) Effects of different serum conditions on osteogenic differentiation of human adipose stem cells in vitro. Stem Cell Res Ther 4: 17.

Lai CF, Chaudhary L, Fausto A, Halstead LR, Ory DS, Avioli LV, Cheng SL (2001) Erk is essential for growth, differentiation, integrin expression, and cell function in human osteoblastic cells. J Biol Chem 276: 14443-14450.

Larranaga A, Alonso-Varona A, Palomares T, Rubio-Azpeitia E, Aldazabal P, Martin FJ, Sarasua JR (2015) Effect of bioactive glass particles on osteogenic 
differentiation of adipose-derived mesenchymal stem cells seeded on lactide and caprolactone based scaffolds. J Biomed Mater Res A 103: 3815-3824.

Lindfors NC, Hyvönen P, Nyyssönen M, Kirjavainen M, Kankare J, Gullichsen E, Salo J (2010) Bioactive glass S53P4 as bone graft substitute in treatment of osteomyelitis. Bone 47: 212-218.

Lindroos B, Boucher S, Chase L, Kuokkanen H, Huhtala H, Haataja R, Vemuri M, Suuronen R, Miettinen S (2009) Serum-free, xeno-free culture media maintain the proliferation rate and multipotentiality of adipose stem cells in vitro. Cytotherapy 11: 958-972.

Liu Q, Cen L, Zhou H, Yin S, Liu G, Liu W, Cao Y, Cui L (2009) The role of the extracellular signalrelated kinase signaling pathway in osteogenic differentiation of human adipose-derived stem cells and in adipogenic transition initiated by dexamethasone. Tissue Eng Part A 15: 3487-3497.

Madanat R, Moritz N, Vedel E, Svedström E, Aro HT (2009) Radio-opaque bioactive glass markers for radiostereometric analysis. Acta Biomater 5: 34973505.

Marino G, Rosso F, Cafiero G, Tortora C, Moraci M, Barbarisi M, Barbarisi A (2010) Beta-tricalcium phosphate 3D scaffold promote alone osteogenic differentiation of human adipose stem cells: in vitro study. J Mater Sci Mater Med 21: 353-363.

Ojansivu M, Vanhatupa S, Björkvik L, Häkkänen H, Kellomäki M, Autio R, Ihalainen JA, Hupa L, Miettinen S (2015) Bioactive glass ions as strong enhancers of osteogenic differentiation in human adipose stem cells. Acta Biomater 21: 190-203.

Peltola MJ, Aitasalo KM, Suonpää JT, Yli-Urpo A, Laippala PJ (2001) In vivo model for frontal sinus and calvarial bone defect obliteration with bioactive glass S53P4 and hydroxyapatite. J Biomed Mater Res 58: 261-269.

Pennisi CP, Dolatshahi-Pirouz A, Foss M, Chevallier J, Fink T, Zachar V, Besenbacher F, Yoshida K (2011) Nanoscale topography reduces fibroblast growth, focal adhesion size and migration-related gene expression on platinum surfaces. Colloids Surf B Biointerfaces 85: 189-197.

Pfaffl MW (2001) A new mathematical model for relative quantification in real-time RT-PCR. Nucleic Acids Res 29: e45.

Pulverer BJ, Kyriakis JM, Avruch J, Nikolakaki E, Woodgett JR (1991) Phosphorylation of c-jun mediated by MAP kinases. Nature 353: 670-674.

Rahaman MN, Day DE, Bal BS, Fu Q, Jung SB, Bonewald LF, Tomsia AP (2011) Bioactive glass in tissue engineering. Acta Biomater 7: 2355-2373.

Rodriguez JP, Gonzalez M, Rios S, Cambiazo V (2004) Cytoskeletal organization of human mesenchymal stem cells (MSC) changes during their osteogenic differentiation. J Cell Biochem 93: 721-731.

Rubinfeld H, Seger R (2005) The ERK cascade: a prototype of MAPK signaling. Mol Biotechnol 31: 151-174.

Salasznyk RM, Klees RF, Williams WA, Boskey A, Plopper GE (2007a) Focal adhesion kinase signaling pathways regulate the osteogenic differentiation of human mesenchymal stem cells. Exp Cell Res 313: 22-37.

Salasznyk RM, Klees RF, Boskey A, Plopper GE (2007b) Activation of FAK is necessary for the osteogenic differentiation of human mesenchymal stem cells on laminin-5. J Cell Biochem 100: 499-514.

Sandor GK, Numminen J, Wolff J, Thesleff T, Miettinen A, Tuovinen VJ, Mannerström B, Patrikoski M, Seppänen R, Miettinen S, Rautiainen M, Ohman J (2014) Adipose stem cells used to reconstruct 13 cases with cranio-maxillofacial hard-tissue defects. Stem Cells Transl Med 3: 530-540.

Schaller MD (2001) Biochemical signals and biological responses elicited by the focal adhesion kinase. Biochim Biophys Acta 1540: 1-21.

Schlaepfer DD, Hauck CR, Sieg DJ (1999) Signaling through focal adhesion kinase. Prog Biophys Mol Biol 71: $435-478$.

Sen B, Uzer G, Samsonraj RM, Xie Z, McGrath C, Styner M, Dudakovic A, van Wijnen AJ, Rubin J (2017) Intranuclear actin structure modulates mesenchymal stem cell differentiation. Stem Cells 35: 1624-1635.

Sen B, Xie Z, Uzer G, Thompson WR, Styner M, Wu X, Rubin J (2015) Intranuclear actin regulates osteogenesis. Stem Cells 33: 3065-3076.

Shie MY, Ding SJ (2013) Integrin binding and MAPK signal pathways in primary cell responses to surface chemistry of calcium silicate cements. Biomaterials 34: 6589-6606.

Shih YR, Tseng KF, Lai HY, Lin CH, Lee OK (2011) Matrix stiffness regulation of integrinmediated mechanotransduction during osteogenic differentiation of human mesenchymal stem cells. J Bone Miner Res 26: 730-738.

Suzuki A, Guicheux J, Palmer G, Miura Y, Oiso Y, Bonjour JP, Caverzasio J (2002) Evidence for a role of p38 MAP kinase in expression of alkaline phosphatase during osteoblastic cell differentiation. Bone 30: 91-98.

Takeuchi Y, Suzawa M, Kikuchi T, Nishida E, Fujita T, Matsumoto T (1997) Differentiation and transforming growth factor-beta receptor down-regulation by collagen-alpha2beta1 integrin interaction is mediated by focal adhesion kinase and its downstream signals in murine osteoblastic cells. J Biol Chem 272: 29309-29316.

Tirkkonen L, Haimi S, Huttunen S, Wolff J, Pirhonen E, Sandor GK, Miettinen S (2013) Osteogenic medium is superior to growth factors in differentiation of human adipose stem cells towards bone-forming cells in 3D culture. Eur Cell Mater 25: 144-158.

Tominaga S, Yamaguchi T, Takahashi S, Hirose F, Osumi T (2005) Negative regulation of adipogenesis from human mesenchymal stem cells by Jun $\mathrm{N}$-terminal kinase. Biochem Biophys Res Commun 326: 499-504.

Tsigkou O, Jones JR, Polak JM, Stevens MM (2009) Differentiation of fetal osteoblasts and formation of mineralized bone nodules by 4555 Bioglass 
conditioned medium in the absence of osteogenic supplements. Biomaterials 30: 3542-3550.

Turunen T, Peltola J, Yli-Urpo A, Happonen RP (2004) Bioactive glass granules as a bone adjunctive material in maxillary sinus floor augmentation. Clin Oral Implants Res 15: 135-141.

Vanhatupa S, Ojansivu M, Autio R, Juntunen M, Miettinen S (2015) Bone morphogenetic pProtein-2 induces donor-dependent osteogenic and adipogenic differentiation in human adipose stem cells. Stem Cells Transl Med 4: 1391-1402.

Viale-Bouroncle S, Gosau M, Morsczeck C (2014a) Collagen I induces the expression of alkaline phosphatase and osteopontin via independent activations of FAK and ERK signalling pathways. Arch Oral Biol 59: 1249-1255.

Viale-Bouroncle S, Gosau M, Morsczeck C (2014b) Laminin regulates the osteogenic differentiation of dental follicle cells via integrin-alpha2/-beta1 and the activation of the FAK/ERK signaling pathway. Cell Tissue Res 357: 345-354.

Virolainen P, Heikkila J, Yli-Urpo A, Vuorio E, Aro HT (1997) Histomorphometric and molecular biologic comparison of bioactive glass granules and autogenous bone grafts in augmentation of bone defect healing. J Biomed Mater Res 35: 9-17.

Waselau M, Patrikoski M, Juntunen M, Kujala K, Kääriäinen M, Kuokkanen H, Sandor GK, Vapaavuori O, Suuronen R, Mannerström B, von Rechenberg B, Miettinen S (2012) Effects of bioactive glass S53P4 or beta-tricalcium phosphate and bone morphogenetic protein- 2 and bone morphogenetic protein-7 on osteogenic differentiation of human adipose stem cells. J Tissue Eng 3: 2041731412467789.

Yourek G, Hussain MA, Mao JJ (2007) Cytoskeletal changes of mesenchymal stem cells during differentiation. ASAIO J 53: 219-228.

Zhang J, Park YD, Bae WJ, El-Fiqi A, Shin SH, Lee EJ, Kim HW, Kim EC (2015) Effects of bioactive cements incorporating zinc-bioglass nanoparticles on odontogenic and angiogenic potential of human dental pulp cells. J Biomater Appl 29: 954-964.

Zuk PA, Zhu M, Mizuno H, Huang J, Futrell JW, Katz AJ, Benhaim P, Lorenz HP, Hedrick MH (2001) Multilineage cells from human adipose tissue: implications for cell-based therapies. Tissue Eng 7: 211-228.

\section{Discussion with Reviewers}

Olivier Guillaume: From the authors' point of view, would they obtain similar conclusions using other sources of MSCs than adipose-derived cells?

Authors: This is definitely an interesting point. Even though there are established criteria, which all the MSCs should fulfill (independent of the source) (Dominici et al., 2006), MSCs from different sources have a certain amount of variation with respect to surface marker expression, differentiation potential as well as immunomodulatory properties
(Murray et al., 2014). Therefore, it is possible that there would be slight differences in the results, if the experiments were conducted with MSCs from some other sources. However, when compared to the bonemarrow derived mesenchymal stem cells (BMSCs), the published results regarding the differentiation potential are highly contradictory (Strioga et al., 2012). Presumably, the differences between ASCs and BMSC s are more reflective of the heterogeneity of the MSC populations and the donor-to-donor variation than any fundamental differences between the cell types. In any case, this is a topic, which would be very interesting to unravel in the upcoming studies.

Olivier Guillaume: Regarding the cell proliferation presented Fig 1B. do the authors have information regarding the diminution observed $21 \mathrm{~d}$, for some of the inhibitor groups? Is it due to (1) a decrease of cell adhesion at day 1 (but then the kinetic of cell proliferation is the same as for the other groups), or (2) due to an influence of the compounds of the cell multiplication behaviour (slowing down its proliferation)?

Authors: Thank you for this interesting question. In the case of the glasses, of the different inhibitions only FAK inhibition significantly decreased the cell proliferation. FAK is an important regulator of cell attachment (Schaller, 2001), which might imply that the decrease in cell proliferation could be at least partially due to the weakened cell attachment. However, even in the presence of the FAK inhibitor the cells were able to spread and the cells were not rounded - which is the typical appearance of poorly attached cells. Thus, the decrease in the proliferation might not be only due to the poor attachment. Unlike on the glasses, in the polystyrene control ERK and JNK inhibitors also significantly decreased the cell proliferation. ERK has a well-known role as a mitogenic factor (Roux and Blenis, 2004), so the attenuation of proliferation in the presence of ERK inhibitor is likely to be explained mainly by the option 2. All in all, these mechanisms are highly complex and, based on the current data, it is impossible to further specify the exact molecular events behind the attenuated proliferation.

Olivier Guillaume: Why is there a difference in term of rugosity/surface roughness between the SEM pictures presented Fig 8B and the optical microscopy illustrations shown Fig 8D?

Authors: Thank you for pointing out this detail. First of all, the glass discs shown in Fig $8 \mathbf{B}$ were imaged after an incubation of $7 \mathrm{~d}$ in culture medium, and by then the glass dissolution has resulted in the formation of silica-rich layer as well as precipitation of hydroxyapatite on the glass surface as seen in Fig $8 \mathrm{~A}(7 \mathrm{~d})$. The surface roughness presented in Fig $8 \mathbf{B}$ on a sub-micron scale mainly indicates the morphological difference between the reacted surface of S53P4 and 1-06 after $7 \mathrm{~d}$ incubation. On the other hand, the surface roughness presented in 
Fig 8D was imaged by confocal optical microscopy $(160 \mu \mathrm{m} \times 160 \mu \mathrm{m}$ area $)$ after the pre-incubation for $24 \mathrm{~h}$ in cell culture medium (the starting point of the cell culture). In these images, the surface roughness mainly originated from the surface polish of the glass discs. Fig 8D aims to provide a comparison of the surface roughness of the glass discs versus the cell culture plastic at the beginning of the cell culture. It thus demonstrates the surface roughness that cells experience when they first associate with the glasses.

Olivier Guillaume: How would the authors envision implementing their results presented here, in order to develop better functional materials for bone regeneration (as brought briefly into the conclusion, related to the cell attachment mechanism study)?

Authors: In general, a thorough understanding of the molecular level cell mechanisms in response to various biomaterials used in TE would improve the safety of clinical treatments (e.g. detection of cancer-related signalling activation) and greatly facilitate a more systematic design approach of novel functional biomaterials and TE constructs. As an example, knowledge of the essential signalling cascades regulating the differentiation fate could eventually lead to a greatly enhanced differentiation induction by using appropriate inhibitor and activator molecules of these cascades. Moreover, correlation of favourable cell responses to specific material features (e.g. surface roughness, ion release) would provide effective means to tailor biomaterials to the desired direction. The present study gave some important insights to the mechanisms of BaGinduced osteogenic commitment and thus set the basis for further characterisation of these complex signalling networks responsible for the BaG-induced favourable cell responses. Such knowledge will ultimately have great potential to support the design and development of better TE-based approaches for the increasing clinical need.

Lia Rimondini: Can you discuss the high variability values observed in some of your experiments?

Authors: Mesenchymal stem cells are known to have relatively large donor-to-donor variation, which will be reflected to all the results obtained with several different MSC donors, as was the case in the present study. Still, despite the relatively large standard deviations in some of our quantitative data, the hASCs from all the donors followed a similar trend in their behaviour, suggesting that the reported results are representative of hASC in general and not only a restricted set of donor cells. In general, when working with mesenchymal stem cells of any origin, it is highly important to conduct the analyses with cells from several donors to take into account the donorto-donor variation. This typically leads to higher variability in the quantitative data when compared to results obtained with established cell lines, which tend to behave with more uniform fashion.

Lia Rimondini: Do you think it may be useful to confirm your results using different BaGs presenting a reactivity gradient?

Authors: This is something, which would be definitely important to do and is the logical next step in the evaluation of the molecular level cell responses to bioactive glasses. Bioactive glass induced cell signalling response is a topic with virtually no previous knowledge and this study was ground breaking in shedding light on this important topic, by analysing hASC attachment and signalling with two slightly different silicate bioactive glasses. However, to be able to fully exploit the molecular level cell data in the development of functional glass-based tissue engineering approaches, it will be important to study these aspects also with different types of glasses. By utilising a set of glasses with a gradient in reactivity or some other feature, it might ultimately be possible to establish an in-depth correlation between the glass properties and cell responses, which would further aid the design of better glasses for regenerative medicine.

\section{Additional References}

Dominici M, Le Blanc K, Mueller I, SlaperCortenbach I, Marini F, Krause D, Deans R, Keating A, Prockop D, Horwitz E (2006) Minimal criteria for defining multipotent mesenchymal stromal cells. The International Society for Cellular Therapy position statement. Cytotherapy 8: 315-317.

Murray IR, West CC, Hardy WR, James AW, Park TS, Nguyen A, Tawonsawatruk T, Lazzari L, Soo C, Peault B (2014) Natural history of mesenchymal stem cells, from vessel walls to culture vessels. Cell Mol Life Sci 71: 1353-1374.

Roux PP, Blenis J (2004) ERK and p38 MAPKactivated protein kinases: a family of protein kinases with diverse biological functions. Microbiol Mol Biol Rev 68: 320-344.

Schaller MD (2001) Biochemical signals and biological responses elicited by the focal adhesion kinase. Biochim Biophys Acta 1540: 1-21.

Strioga M, Viswanathan S, Darinskas A, Slaby O, Michalek J (2012) Same or not the same? Comparison of adipose tissue-derived versus bone marrowderived mesenchymal stem and stromal cells. Stem Cells Dev 21: 2724-2752.

Editor's note: The Scientific Editor responsible for this paper was Mauro Alini. 